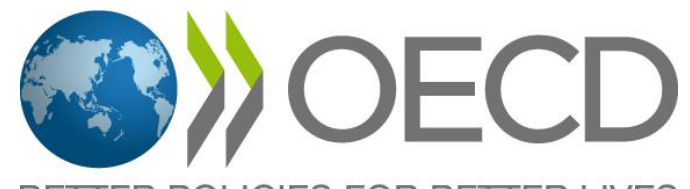

BETTER POLICIES FOR BETTER LIVES

\title{
LOCAL ENTREPRENEURSHIP ECOSYSTEMS AND EMERGING
}

\section{INDUSTRIES}

Case Study of

Mazowieckie, Poland 


\section{Local Entrepreneurship Ecosystems and Emerging Industries}

Case Study of Mazowieckie, Poland

August 2019 


\section{ABOUT THE OECD}

The OECD is a multi-disciplinary inter-governmental organisation of 36 member countries which engages in its work an increasing number of non-members from all regions of the world. The Organisation's core mission today is to help governments work together towards a stronger, cleaner, fairer global economy. Through its network of 250 specialised committees and working groups, the OECD provides a setting where governments compare policy experiences, seek answers to common problems, identify good practice, and coordinate domestic and international policies. More information available: www.oecd.org.

\section{ABOUT OECD LOCAL ECONOMIC AND EMPLOYMENT DEVELOPMENT (LEED) WORKING PAPERS}

A series of working papers from the OECD Local Economic and Employment Development (LEED) Programme. The LEED Programme identifies, analyses and disseminates innovative ideas for local development, governance and the social economy. Governments work with the LEED Programme to generate innovative guidance on policies to support employment creation and economic development through locally based initiatives.

This paper is published under the responsibility of the Secretary-General of the OECD. The opinions expressed and the arguments employed herein do not necessarily reflect the official views of OECD member countries.

This paper was authorised for publication by Lamia Kamal-Chaoui, Director, Centre for Entrepreneurship, SMEs, Regions and Cities, OECD.

This document, as well as any statistical data and map included herein, are without prejudice to the status of or sovereignty over any territory, to the delimitation of international frontiers and boundaries and to the name of any territory, city or area.

Cover: @Shutterstock

(C) OECD 2019

You can copy, download or print OECD content for your own use, and you can include excerpts from OECD publications, databases and multimedia products in your own documents, presentations, blogs, websites and teaching materials, provided that suitable acknowledgement of OECD as source and copyright owner is given. All requests for public or commercial use and translation rights should be submitted to rights@ oecd.org. 


\section{Foreword}

This report examines the local entrepreneurship ecosystem of the Mazowieckie region in Poland and its capacity to promote productivity upgrading and industrial renewal. It forms part of the OECD's work stream on local entrepreneurship ecosystems and emerging industries.

The OECD local entrepreneurship ecosystems work examines the main dimensions of local entrepreneurship ecosystems that affect innovative start-ups, scale-ups and innovation in existing enterprises in case study regions. It relates the policy development of local entrepreneurship ecosystems to the principle of regional smart specialisation, and investigates how smart specialisation strategies are helping to strengthen entrepreneurship and innovation in regions.

Mazowieckie is a very interesting case study region for a number of reasons. It has a very diverse regional industrial structure offering many opportunities to develop smart specialisations based on related and unrelated variety. It has strong potential entrepreneurship ecosystem 'anchors' in the form of large domestic and international firms and higher education institutions which are major sources of knowledge, skills and networks that can help drive innovative start-ups, scale-ups and SME innovation in the region. It also has a significant polarisation between a dense and innovative core in Warsaw at the centre of the region, where there are many high-technology manufacturing and knowledge-intensive services firms, and a lower density periphery, where there are more traditional sectors and lower innovation levels. This requires a smart specialisation strategy capable of binding them together and creating a sum greater than the parts.

This report examines Mazowieckie's local entrepreneurship ecosystem and regional smart specialisation approach. It identifies bottlenecks and enablers in the local entrepreneurship ecosystem and makes policy recommendations on how to further strengthen local entrepreneurship and industrial renewal. The report offers a number of policy suggestions and models for Mazowickie and for other regions interested in promoting entrepreneurship and emerging industries. 


\section{Acknowledgements}

This report was prepared by the Centre for Entrepreneurship, SMEs, Regions and Cities (CFE) of the Organisation for Economic Co-operation and Development (OECD) led by Lamia Kamal-Chaoui, Director. It has been supported by the Polish Ministry of Investment and Development and the Regional Government of Mazowieckie. It forms part of the work of the Local Economic and Employment Development (LEED) Committee of the OECD on local entrepreneurship ecosystems.

The project was led by Jonathan Potter, Head of the Entrepreneurship Policy and Analysis Unit, CFE, OECD, and Sandra Hannig, Policy Analyst, CFE, OECD. The report was drafted by a team involving Björn Asheim (University of Stavanger, Norway and University of Lund, Sweden), Artur Bartoszewicz (Warsaw School of Economics), Chay Brooks (University of Sheffield, United Kingdom), Martina Fuchs (University of Cologne, Germany), Sandra Hannig (OECD), Jonathan Potter (OECD), and Tim Vorley (University of Sheffield, United Kingdom). Inputs on the local entrepreneurship ecosystem scoring were provided by Tomasz Brodzicki, Krystyna Gawlikowska-Hueckel and Stanisław Umiński of the Institute for Development, Sopot, Poland.

The project was co-ordinated in Poland by Przemysław Herman, Ministry of Investment and Development, and Jacek Furkałowski and Hubert Szczepkowski of the Regional Government Authority of Mazowieckie.

Many individuals and organisations in the region provided important information. A wide range of stakeholders participated in meetings with the OECD review panel during an OECD study mission to the region. The participating organisations included the departments and political representatives of Mazowieckie Regional Government, the Mazovian Development Agency, Mazovian Industrial and Technological Park, Płock Region Chamber of Commerce, MITEF Enterprise Forum Poland, Warsaw University of Technology, Mazovian credit guarantee fund, Bank Gospodarstwa Krajowego BGK Bank, SatAgro, Ecorys, VIGO System S.A., Infotech Production, AgroBioCluster, medical sector cluster, Leviatan Foundation, Institute for Sustainable Technologies, Institute of Aviation, Mazovian Energy Agency, Romanticism Museum in Opinogóra, Mazovian Centre of Social Policy, Warsaw Commuter Railway, Mazowieckie Railways, Warsaw Regional Employment Office, Institute of Physics Polish Academy of Sciences, Mazovian Local Government Teacher Training Centre, and Targowa Creativity Centre.

The draft report was discussed at a stakeholder workshop on 5 November 2018 in Warsaw. The participants in this workshop provided comments that were taken into account in the finalisation of the report. 


\section{Table of contents}

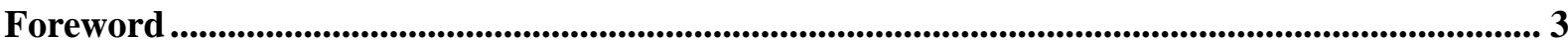

Acknowledgements ............................................................................................................................................. 4

Acronyms and abbreviations....................................................................................................................... 8

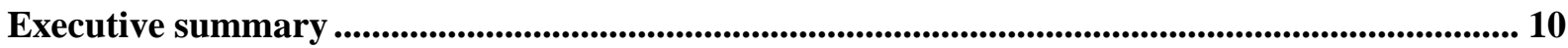

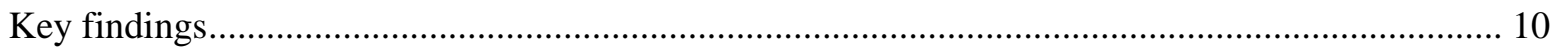

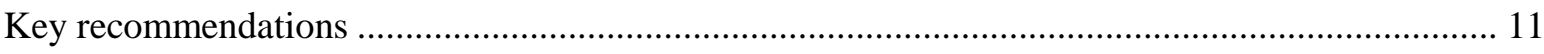

1. Overall assessment and recommendations........................................................................................ 13

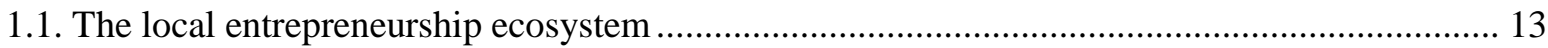

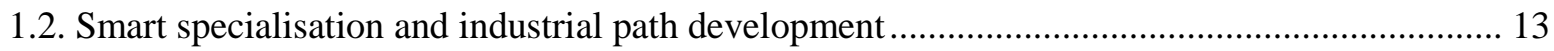

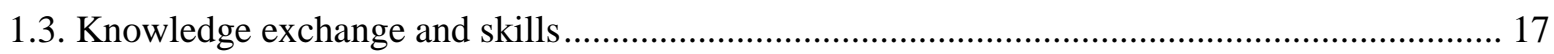

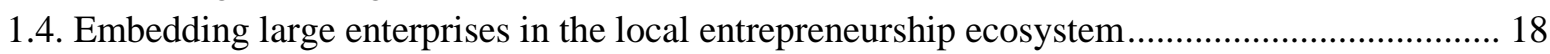

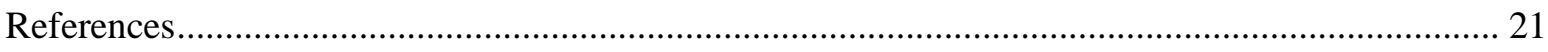

2. The Mazowieckie entrepreneurship ecosystem and smart specialisation policy ......................... 22

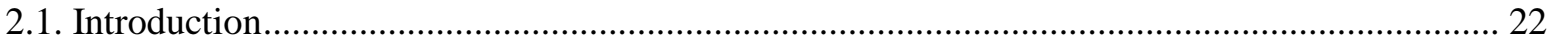

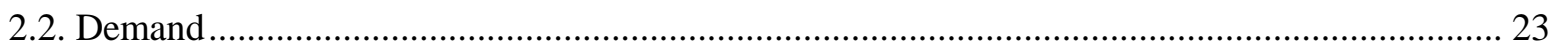

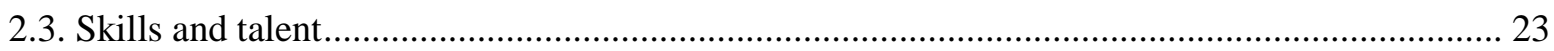

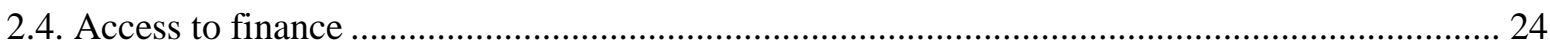

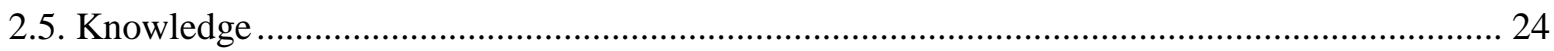

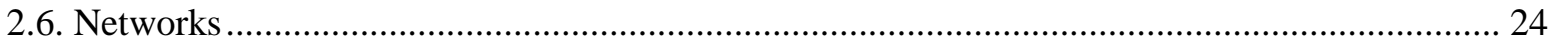

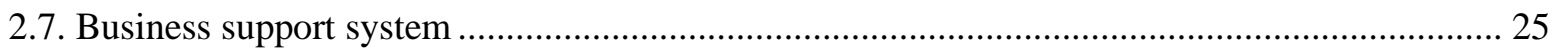

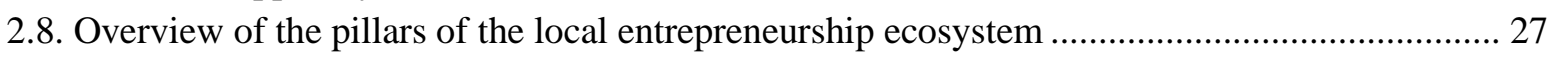

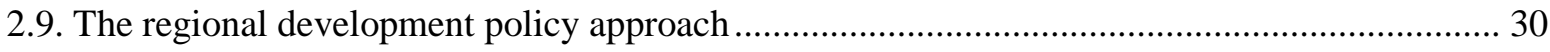

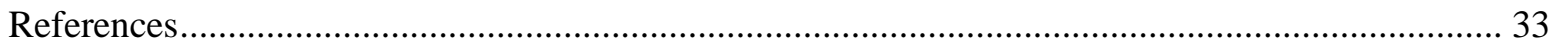

3. Smart specialisation and industry path development ..................................................................... 34

3.1. Adapting to regional pre-conditions in industry path development strategies........................... 34

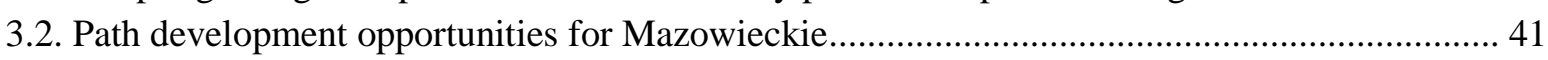

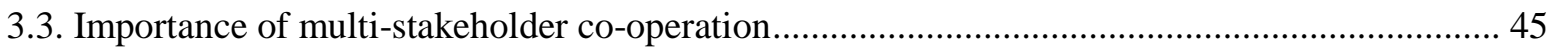

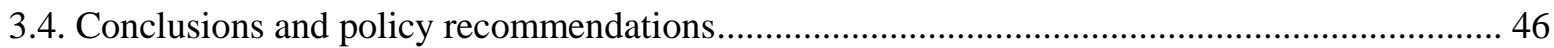

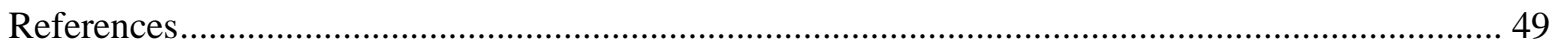

4. Knowledge exchange and skills .................................................................................................................. 50

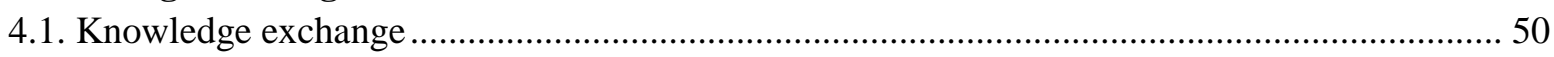

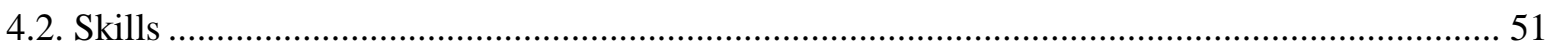

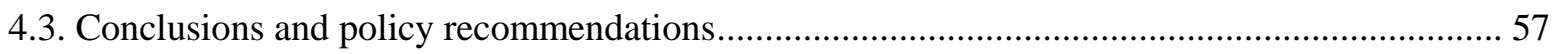

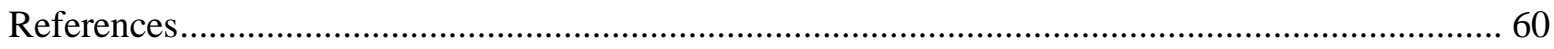


5. Embedding large enterprises in the local entrepreneurship ecosystem

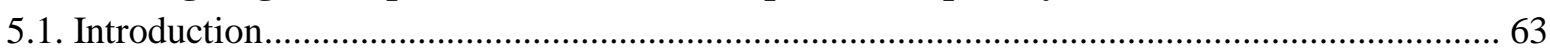

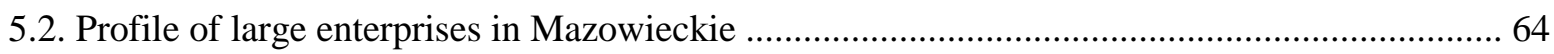

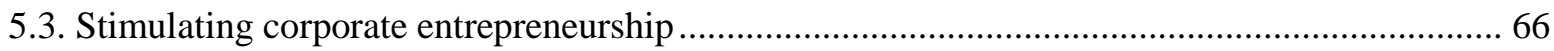

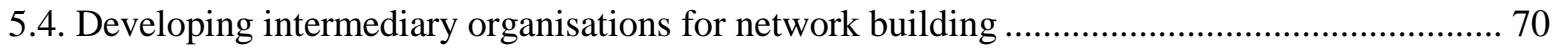

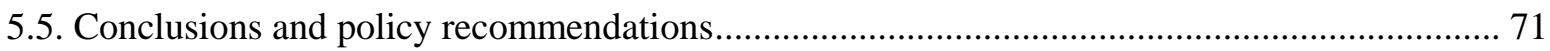

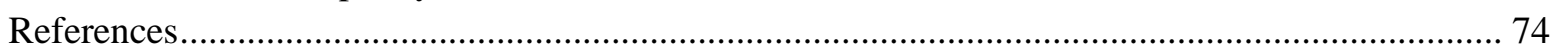

Annex A. Data sources for local entrepreneurship ecosystem comparisons .................................... 75

Annex B. Conceptual framework for smart specialisation and path development opportunity

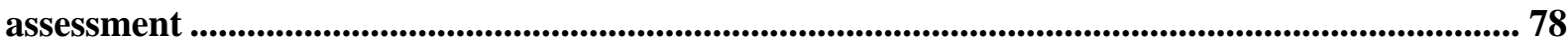

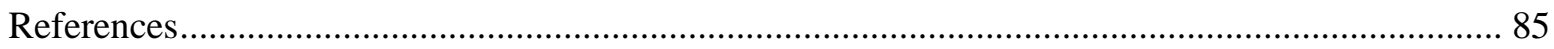

\section{Tables}

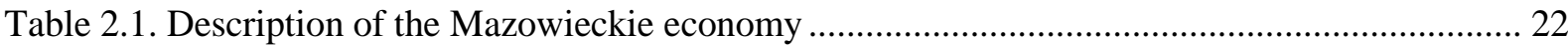

Table 2.2. Local entrepreneurship ecosystem indicators by ecosystem pillar and Polish region-

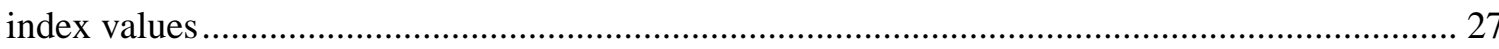

Table 2.3. Local entrepreneurship ecosystem indicators by ecosystem pillar and Polish region -

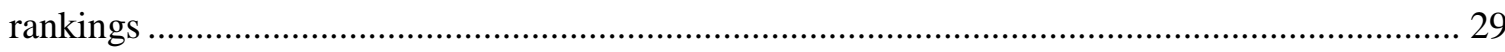

Table 2.4. Mazowieckie smart specialisation strategy - the selected regional specialisations ............. 32

Table 3.1. Characterisation of Mazowieckie's regional pre-conditions for industrial path

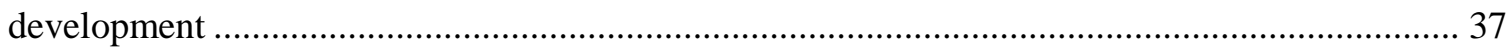

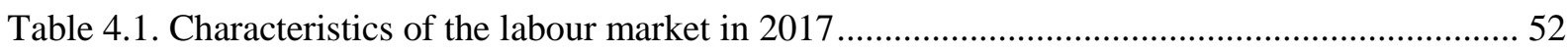

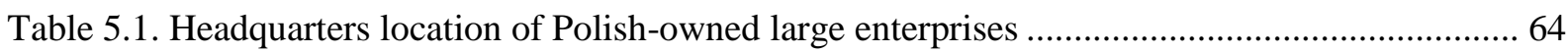

Table 5.2. Number of foreign investors in Mazowieckie, end 2015 ................................................. 65

\section{Figures}

Figure 4.1. Education of employed persons in Mazowieckie ( $1^{\text {st }}$ quarter 2018) ................................. 53

\section{Boxes}

Box 1.1. Recommendations on smart specialisation and industry path development .......................... 16

Box 1.2. Recommendations on knowledge exchange and skills ................................................... 18

Box 1.3. Recommendations on embedding large firms in the local entrepreneurship ecosystem ........ 20

Box 3.1. A strategy for unrelated diversification and new path creation - Emilia Romagna, Italy ...... 38

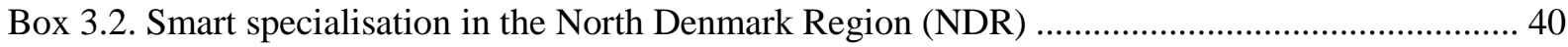

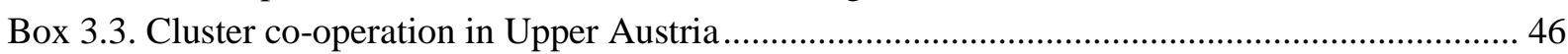

Box 3.4. Recommendations on smart specialisation and industry path development .......................... 48

Box 4.1. Policy to build mutual trust and collaboration, Stuttgart, Germany ...................................... 51

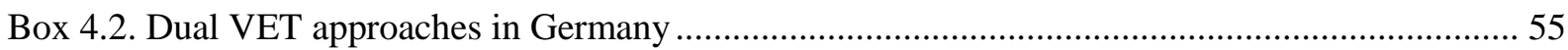


Box 4.3. Job Security Councils, Sweden 57

Box 4.4. Recommendations on knowledge exchange and skills

Box 5.1. Role of the Uppsala BIO cluster organisation in promoting large firm entrepreneurship support in Uppsala, Sweden 67

Box 5.2. The Aerospace Valley Cluster and the Airbus BizLab accelerator, Midi-Pyrenees, France .. 68

Box 5.3. Recommendations on embedding large firms in the local entrepreneurship ecosystem 73 


\section{Acronyms and abbreviations}

$\begin{array}{ll}\text { B2B } & \text { Business to business } \\ \text { BEI } & \text { Business environment institution } \\ \text { BPO } & \text { Business process outsourcing } \\ \text { BSO } & \text { Business support organisation } \\ \text { CEE } & \text { Central and Eastern Europe } \\ \text { EDP } & \text { Entrepreneurial discovery process } \\ \text { EEG } & \text { Evolutionary economic geography } \\ \text { EEI } & \text { Entrepreneurial Ecosystem Index } \\ \text { EER } & \text { European Entrepreneurial Region } \\ \text { ERDF } & \text { European Regional Development Fund } \\ \text { EU } & \text { European Union } \\ \text { FDI } & \text { Foreign direct investment } \\ \text { GDP } & \text { Gross domestic product } \\ \text { GE } & \text { General Electric } \\ \text { GPN } & \text { Global production network } \\ \text { GVC } & \text { Global value chain } \\ \text { HEI } & \text { Higher education institution } \\ \text { ICT } & \text { Information and communications technology } \\ \text { IT } & \text { Information technology } \\ \text { ITO } & \text { Information technology outsourcing } \\ \text { KET } & \text { Key enabling technology } \\ \text { KFS } & \text { Kommunala Företagens Samorganisation (a Job Security Council in Sweden) } \\ \text { KIS } & \text { Knowledge-intensive services } \\ \text { MBPR } & \text { Mazowieckie Regional Planning Office } \\ \text { MHT } & \text { Medium high-tech } \\ \text { MNE } & \text { Multinational enterprise } \\ \text { MPNT } & \text { Mazowieckie Science and Technology Park } \\ \text { NDR } & \text { North Denmark Region } \\ \text { NGO } & \text { Non-governmental organisation } \\ \text { OECD } & \text { Organisation for Economic Co-operation and Development } \\ \text { PARP } & \text { Polish Agency for Enterprise Development } \\ \text { PE } & \text { Private equity } \\ \text { PFR } & \text { Polish Development Fund } \\ \text { PIAH } & \text { Polish Investment and Trade Agency } \\ \text { PIRLS } & \text { Progress in International Reading Literacy Study } \\ \text { PISA } & \text { Programme for International Student Assessment (of the OECD) } \\ & \end{array}$




$\begin{array}{ll}\text { PLN } & \text { Polish zloty } \\ \text { PNT } & \text { Science and Technology Park SWIERK } \\ \text { PPPT } & \text { Plock Industrial and Technology Park } \\ \text { PRO } & \text { Public research organisation } \\ \text { PSIK } & \text { Polish Private Equity and Venture Capital Association } \\ \text { R\&D } & \text { Research and development } \\ \text { R\&D\&I } & \text { Research, development and innovation } \\ \text { RII } & \text { Regional innovation index } \\ \text { RIS } & \text { Regional Innovation Strategy } \\ \text { RIS3 } & \text { Research and Innovation Smart Specialisation Strategy } \\ \text { SEZ } & \text { Special economic zone } \\ \text { SME } & \text { Small and medium-sized enterprise } \\ \text { SSC } & \text { Shared service centre } \\ \text { TIMMS } & \text { Trends in International Mathematics and Science Study } \\ \text { TRR } & \text { Trygghetsrådet (a Job Security Council in Sweden) } \\ \text { TTO } & \text { Technology transfer office } \\ \text { VC } & \text { Venture capital } \\ \text { VET } & \text { Vocational education and training } \\ \text { WMA } & \text { Warsaw Metropolitan Area } \\ \text { WSA } & \text { Warsaw Stock Exchange }\end{array}$




\section{Executive summary}

Mazowieckie is located in the central-eastern part of Poland on the Mazowieckie Lowland. It is the largest and most populated region of Poland. It is also the most economically developed, producing approximately $22 \%$ of national gross domestic product (GDP). The main administrative centre is Warsaw, the capital of Poland, which produces nearly $60 \%$ of the region's GDP. Mazowieckie also has the largest rural population in Poland, with one in four people working in agriculture.

\section{Key findings}

\section{Spatial disparities within the region}

Mazowieckie's economy has a dual structure. There is a high income and dense core in Warsaw with a diverse set of industries, driven to a significant extent by success in attracting FDI. Surrounding that the periphery is more specialised on agriculture and food and various traditional industries; with weaker economic and labour market performance. Some 105 of the 500 poorest communes in Poland are in the region.

There is a mutually beneficial opportunity to strengthen the alignment of the economic development strategy between the centre and periphery of the region, and a need to recognise the interdependence for future growth. In particular, policy needs to develop strategies to diffuse the innovative capacity and capabilities of the core to peripheral urban centres and rural areas.

\section{Supporting innovative start-ups, scale-ups and SMEs}

Central and regional government policy initiatives are playing an important role in promoting innovative start-ups, scale-ups and SME innovation in the region. Warsaw has an active start-up community and important business development infrastructures such as accelerators and incubators, which is witness to a healthy local entrepreneurship ecosystem overall. Nevertheless, some aspects of the local ecosystem need more policy attention, such as access to finance for entrepreneurs. Furthermore, there are particular constraints in access to resources for entrepreneurship in the periphery of the region. More targeted efforts are also needed to identify potential scale-up enterprises, particularly in key smart specialisations, and to support them with a relevant package of measures, including mentoring. There is also a need to ensure that traditional SMEs with growth and innovation potential access relevant business support, including in the periphery of the region.

\section{Importance of new path development}

Mazowieckie has a broad economic development strategy, reflecting the diversity of its economy. The success of a smart specialisation strategy in Mazowieckie will be contingent on efforts to identify R\&D, technological and industrial strengths in the region that can be used as the basis to develop future diversified specialisations based on related variety and 
unrelated knowledge combinations supported by use of Key Enabling Technologies. This can be driven by a reinforced Entrepreneurial Discovery Process, which needs to actively involve a wide range of entrepreneurially-minded stakeholders from business and research.

\section{Building trust and connections for knowledge exchange}

Despite a pro-business environment, a challenge for Mazowieckie is a lack of social capital and mutual trust, which constrains collaboration among businesses and with higher education institutions and research organisations for innovation and entrepreneurship. An important role of the Mazowieckie regional government moving forward is therefore to build trust and connections across public and private stakeholders throughout the region. Collaboration initiatives in areas of research and skills development and promoted through organisations like the regional clusters can be effective in creating repeated interactions generative of trust.

\section{Developing and utilising skills}

Emerging labour and skill shortages are becoming a growing challenge in Mazowieckie, particularly in the centre. Over the past decade, this issue has been compounded by the outmigration of skilled individuals, which makes the attraction of skilled immigrants and Polish re-migrants a policy imperative. The skills generated by the higher education and vocational education and training systems are also lacking to some extent in transversal competences such as entrepreneurship, digital skills and social skills, while demand for certain technical skills also exceeds supply. Further development of dual training approaches can be part of the solution.

\section{Embedding large enterprises}

Mazowieckie, particularly Warsaw, has been very successful in attracting foreign direct investment and the headquarters of large domestic firms. However, the jobs created tend to be more process-based roles and in general they have limited collaboration or engagement with universities or other companies in Mazowieckie, and offer few opportunities to local firms in terms of access to international supply chains or global production networks. A shift to more skills and knowledge-intensive activities could greatly promote the capacity of these large firms to engage as anchors in the local entrepreneurship ecosystem, facilitated by developing a clear and consistent place-based value proposition to inward investors that signals the potential for them to access important regional assets and linkages. There is also potential to work with existing large firms in the region to increase their involvement in initiatives for corporate entrepreneurship co-operation initiatives driven by network intermediaries.

\section{Key recommendations}

The report makes detailed recommendations on promoting entrepreneurship and new industry development paths to drive productivity growth. Central to this is improving the local labour market and knowledge exchange, as well as leveraging the value of higher education institutions and large firms. Key recommended actions include the following:

- Adopt a dual policy approach to promote specific sub-regional smart specialisation strategies for the core and the periphery and promote innovation diffusion between the two. 
- Promote new path development in the core of the region through related and unrelated diversification and new industry creation using knowledge about key enabling technologies (KETs) from universities and other firms in high-technology manufacturing and knowledge-intensive business services.

- Promote path upgrading of traditional sectors in the periphery of the region especially by combining agriculture with KETs such as biotechnology and nanotechnology for uses including food conservation, packaging, functional food (with health properties) and organic food.

- Attract and promote the integration of highly skilled international migrants and Polish re-migrants into local labour markets in accordance with foreseeable skill shortages and expand dual training initiatives.

- Foster confidence building and the development of mutual trust between local stakeholders for stronger collaboration by supporting networking and collaborative projects for entrepreneurship, innovation and skills development.

- Signal the high entrepreneurial potential of the region and build its talent and skills in order to attract more skills and knowledge-intensive inward investment.

- Involve large enterprises in supporting entrepreneurship initiatives such as accelators and incubators and expand and co-ordinate intermediary organisations responsible for building regional business and research networks. 


\section{Overall assessment and recommendations}

This section summarises the findings and recommendations of the report. It examines conditions for entrepreneurship and emerging industries in Mazowieckie and makes policy recommendations in the areas of economic diversification, labour market development, knowledge exchange and embedding large firms in the local entrepreneurship ecosystem.

\subsection{The local entrepreneurship ecosystem}

\section{The ecosystem is strong overall - priorities are in improving trust, networks and access to finance}

Data comparing Mazowieckie with other regions in Poland across key dimensions of local entrepreneurship ecosystems shows that Mazowieckie is the highest ranked region overall in Poland for the vitality of its overall local entrepreneurship ecosystem. However, its scores are uneven across different local entrepreneurship ecosystem pillars. It is the top ranked region in Poland in the areas of entrepreneurship culture, demand, talent and skills, new knowledge, intermediate services and leadership. It also ranks very well on infrastructure. However, it has a relatively weak performance on three local entrepreneurship ecosystem pillars, namely formal institutions, networks and access to finance. This suggests the importance of policy efforts to improve trust, networks and access to finance in the region.

\subsection{Smart specialisation and industrial path development}

\section{The region has developed a smart specialisation strategy}

The European Union (EU) has made the development of Research and Innovation Smart Specialisation Strategies (RIS3) at national or regional level a prerequisite for EU Member States to access the European Regional Development Fund (ERDF) for research and innovation activities. In line with this guidance, the Mazowieckie regional government has developed a regional smart specialisation strategy to help prioritise and steer its regional innovation policy interventions. Using the smart specialisation approach implies identifying strategic sectors of existing and/or potential competitive advantage where the region can specialise, building on and developing its existing strengths and capabilities.

\section{New path development through diversification offers the greatest long-term rewards}

Regional economies can evolve along various industrial transition pathways. These include path upgrading, path diversification and path emergence. Traditional regional development approaches have largely focused on path upgrading through renewal, climbing global 
production networks (GPNs) or niche development. These approaches offer short and medium-term opportunities for productivity growth. However, strategies for new path development through diversification and path emergence promote more diversity in a region and offer greater opportunities for long-term regional productivity growth. These approaches focus on diversification into related and unrelated industries, importation of industries that are new to a region and stimulating the emergence of entirely new industries. The optimal approach in Mazowieckie is likely to involve a combination of path upgrading for short and medium-term development and diversification and path emergence for longterm development.

\section{The Mazowieckie strategy would benefit from greater prioritisation and greater focus on path diversification and path emergence}

The main goal of Mazowieckie's smart specialisation strategy is promoting economic growth in the region through the development of export-oriented industrial production, especially in medium and high-tech manufacturing and agri-food sectors. This involves supporting the development of new technologies through research and improving the productivity and competitiveness of the region's advanced agricultural sector.

The smart specialisation strategy identifies the following four smart specialisations:

- Safe Food.

- Intelligent Management Systems.

- Professional Services for Business.

- High Quality of Life.

This appears to conflate 'sector' priorities (the first three priorities) with overall economic goals (the fourth priority). In addition, each specialisation is broad and reflects a traditional path upgrading approach rather than a broader strategy for diversified specialisation. The regional government should therefore consider making adjustments in any renewal of the strategy, in particular as envisaged for the new EU financial programming period 20212027.

Refining the strategy will require identifying the key specific opportunities and mobilising actors to pursue them through an active "entrepreneurial discovery process" (EDP). While the regional government used an EDP for the design of the existing strategy, it involved a narrow range of stakeholders, with limited participation from small and medium-sized enterprises (SMEs) for example. The success of a renewed smart specialisation strategy will ultimately depend on the successful application of an EDP that mobilises multiple actors with entrepreneurial mindsets across the region to identify and pursue the real R\&D, technological and industrial strengths of the region and its two sub-regional components.

\section{There is uneven spatial development within the region}

Mazowieckie is the richest and most innovative region in Poland, with GDP per capita standing at $160 \%$ of the national average. Taken together, the centre and periphery of Mazowieckie are classed by the European Regional Innovation Scoreboard as a "moderate innovator" region, below the "strong innovator" and "innovation leader" regions of the EU.

However, there are important spatial disparites within the region. Warsaw is a major global city and the wealthiest capital in Central and Eastern Europe (CEE). It outperforms the 
region's periphery on indicators such as income, education levels, and occupational structure. It is home to the four leading Polish universities and has a diversified industrial structure underpinned by advanced private service industries, public administration, the highest concentration of electronics and high-tech industry in Poland and the largest financial services hub within CEE. It also has a large number and variety of innovation system actors, networks and institutions. Warsaw offers favourable conditions for new path development involving radical and high-tech global innovation.

Conditions for new path development based on radical innovation are weaker in the periphery. The periphery has a more specialised industrial structure, dominated by agriculture, construction and some heavy industry. It also has fewer relevant innovation actors and organisations and a lack of networks and social capital. Nonetheless, the periphery is still a propitious location for incremental innovation in more traditional industries and development through path upgrading, especially in the bio-and agri-food industries. Indeed, some smaller cities, such as Radom, Płock and Pruszków have already shown signs of recovery and have transitioned into new industries.

\section{A dual strategy is therefore appropriate - path diversification and emergence in the centre and path upgrading in the periphery}

The existence of polarised pre-conditions for industry path development between the centre and the periphery of Mazowieckie implies that it would be most effective to adopt a dual policy approach with distinct but integrated sub-regional smart specialisation strategies.

In Warsaw, there is strong capacity to promote new path development through related and unrelated diversification and new industry creation. The basis can be the integration of knowledge into existing firms in the smart specialisation areas about key enabling technologies (KETs) from universities and other firms in fields such as electronics, ICT, nanotechnology, biotechnology, and photonics. This can be complemented with selected foreign direct investment (FDI) attraction and support for start-ups and scale-ups. There is strong potential in knowledge-intensive business services, including big data analytics, data storage and remote health diagostics. There is also potential in high-technology manufacturing including energy, medicine and pharmaceuticals. There are further opportunities for upgrading alongside this main strategy.

In the periphery, path upgrading of traditional sectors is most realistic strategy. This can focus on renewal and niche development in food production, especially by combining agriculture with KETs such as biotechnology and nanotechnology for uses including food conservation, packaging, functional food (with health properties) and organic food. There are further opportunities for upgrading in other traditional industries alongside this main strategy. 


\section{Box 1.1. Recommendations on smart specialisation and industry path development}

\section{Adapting industry path development strategies to regional pre-conditions}

1. Increase policy emphasis on new path development aimed at diversifying the economy into more technologically advanced activities with greater knowledge complexity.

2. Increase prioritisation in the smart specialisation strategy to emphasise a small number of more specific specialisations.

3. Adopt a policy approach that is designed to meet the distinct needs of both the centre and the periphery of the region.

4. Strengthen the entrepreneurial discovery process by actively engaging with multiple stakeholders to identify and mobilise actions behind the main opportunities.

\section{Path diversification and path creation in the centre}

5. Develop an R\&D based strategy to capitalise on the Warsaw's strong research base in biotechnology, ICT, nanotechnology, electronics and photonics to promote diversification and new industry creation in business services (e.g. for big data analytics, data storage, remote health diagnostics), and in high technology manufacturing (e.g. in energy, medicine and pharmaceuticals).

6. Accelerate the commercialisation of new research results through stimulating close co-operation between HEIs and industry as well as competence building to strengthen the absorptive capacity of SMEs.

7. Use public procurement for innovation to facilitate the development and production of products based on the core research and technological competences of the region.

8. Support an upgrade in the business services sector by moving from labour cost competition to a model based on competing on innovation strengths, including leveraging the proximity to several high-quality research universities.

9. Promote related diversification in transport technology by capitalising on the competent research milieu in aeronautics and space technology at the Warsaw University of Technology.

10. Pursue path importation through FDI to support diversification in the short term, including through developing production capacities in areas of research specialisation.

\section{Path upgrading in the periphery}

11. Upgrade food production from low value-added raw produce towards processed products with higher complexity and quality in the final market while also moving up the value chain in export.

12. Support new industry creation by employing KETs such as biotechnology and nanotechnology in food production, (e.g. for food conservation, packaging, functional food, and organic food). 
13. Pursue path upgrades in traditional industries that have shown an interest in innovation such as construction, petrochemical, energy, electronics, metals and machinery, and footwear.

14. Strengthen the absorptive capacity of SMEs by increasing their R\&D competences as well as workforce and management skills.

\subsection{Knowledge exchange and skills}

\section{Networking and trust across actors need to be strengthened to support knowledge exchange}

In Mazowieckie, a range of networks at different scales support knowledge exchange for entrepreneurship and emerging industries. These networks include large firms, HEIs, governments, economic development agencies and chambers of commerce. However, the networks are stronger in the centre than the periphery of the region. Furthermore, conditions for network building need to be strengthened. First, incentives for HEI engagement with industry need to be increased at the level of the HEI, department and individual researcher. Second, as in other CEE countries (Marinelli et al., 2017), lack of trust is a barrier to knowledge exchange among actors in Mazowieckie. Policy can build trust among actors in the long term with measures that foster multi-actor collaboration.

\section{Actions are needed to meet future skill needs}

Mazowieckie has a well-developed education and training system. Warsaw is home to a number of renowned and prestigious universities. There is also a dense vocational and training (VET) system, with 620 vocational schools and 76000 students in Mazowieckie, most of them located in Warsaw.

Mazowieckie nevertheless suffers from current and emerging skills shortages in certain specific economic sectors are likely to constrain regional industrial transition both in the centre and in smaller cities and rural areas in the periphery. This implies a need to increase the pool of skills in the region. While Poland attracts immigrants from neighbouring countries such as Ukraine, Belarus and the Russian Federation, these immigrants usually work in low-skilled segments of the economy. The region also suffers from out-migration of skilled individuals. The attraction of skilled immigrants and re-migrants to the region is therefore a key policy priority (OECD, 2016; Di Berardino et al., 2017). The pool of skills can also be strengthened through support to female labour market participation (e.g. through childcare policy).

More attention is also needed to leveraging the VET system to support industrial transition. Mazowieckie is already making efforts to promote a better image of VET and could further benefit from increasing the integration of local large and small businesses in the design and delivery of training. In particular, there is scope to increase co-operation between VET colleges and companies in dual training initiatives whereby apprentices are trained in both colleges and firms. Dual training systems appear to be most effective in regions with a sophisticated VET system and long tradition in skilled work in manufacturing. This suggests that dual VET initiatives are a promising prospect in Mazowieckie, even though they may not be appropriate across the whole of Poland. 
Fourth, although the region has attracted substantial FDI, many of these companies have so far relied on internal training solutions (Dománski, 2003). This highlights the need to promote the regional embeddedness of FDI within the higher education and VET systems.

A further issue relates to retaining skilled labour when companies are forced to downsize in times of crisis. Polish law is favourable in this respect, allowing firms to reduce working time for operational or seasonal reasons. Public financial support for reduced working hours also offers an instrument for companies to keep on highly qualified staff during a crisis. At the same time, support for the transfer of skilled and experienced staff to new firms is also critical as, for example, companies go bankrupt, so that skilled labour is not lost to the regional economy. Mazowieckie could get inspiration from initiatives implemented in other countries, such as job security councils in Sweden.

Box 1.2. Recommendations on knowledge exchange and skills

Knowledge exchange

1. Increase incentives for HEI engagement with industry at the level of the HEI, department and individual researcher.

2. Provide a range of forums and initiatives to foster multi-actor collaboration and help build mutual trust for knowledge exchange, including by organising regional conferences, meetings, and workshops involving diverse actors to identify win-win projects and initiatives.

\section{Labour market}

3. Promote greater integration of highly-skilled international (re)migrants and women into the labour force to help address future skill shortages.

4. Encourage stronger collaboration between the higher education and vocational education and training systems and businesses, supporting foreign direct investors, large domestic firms and SMEs in making inputs to the identification of skill needs, the design of training and courses and participating in teaching.

5. Include skills issues in the discussions of the smart specialisation working groups to build a shared narrative on future skills and training needs and potential collaborations.

6. Support the development of job security councils to assist with negotiating reduced working hours arrangements and transferring skilled labour from firms affected by crises and redundancies.

\subsection{Embedding large enterprises in the local entrepreneurship ecosystem}

\section{Large enterprises have strong potential to stimulate local entrepreneurship and innovation}

In many advanced regional economies, large firms boost local entrepreneurship and innovation through being active in corporate entrepreneurship and getting involved in a range of local innovation and skills development collaborations.

There is a substantial large firm presence in Mazowieckie, both in FDI and the headquarters and operations of large domestic firms. This provides an opportunity for large firms to help 
drive entrepreneurship and innovation in the region. The impacts are likely to be most marked where the large firms are both locally embedded and where they adopt strategies that promote entrepreneurship and innovation. In Mazowieckie, the photonics industry is a good example of how large firms have helped generate an SME-dominated industry in the region by acting as sophisticated customers. Another example is General Electric's (GE) funding of the Institute of Aviation to work with Polish scientists and engineers and increase $\mathrm{R} \& \mathrm{D}$ intensity in the sector.

\section{The innovation content of foreign direct investment needs to be increased}

A key factor influencing the probability that large enterprises will stimulate entrepreneurship and innovation in a region is the extent to which their operations have high innovation content. FDI to Mazowieckie typically has relatively low levels of R\&D activity (Salameh et al., 2011) although there are examples of recent R\&D-based investments. An upgrading in the innovation level of the region's FDI can be achieved by marketing a regional value proposition based on the start-up dynamism, high skills and $R \& D$ assets in the region, emphasising for example the existing high intensity of $R \& D$ in the region and Warsaw's strong start-up community. The other side of the challenge is to more actively develop the value proposition by continuing to build the region's entrepreneurship, innovation and skills strengths.

\section{There are opportunities to increase large firm engagement in entrepreneurship support}

There are examples of how large firms in Mazowieckie have established incubators and accelerators and providing a range of mentoring, consulting and financial support to innovative start-ups and scale-ups. They include the Google Campus for entrepreneurs and start-up founders and the Google for Entrepreneurs programme. However, these types of activities are relatively rare among large firms in Mazowieckie. Large firms could initially be involved in public infrastructures to support start-ups and scale-ups, such as the public Centres of Entrepreneurship, incubators and accelerators, both as investors, providers of advice and mentoring and as networking partners.

\section{Regional government should strengthen its network intermediary function}

Mazowieckie's large firms are often strongly tied to national and international networks, reflecting the national headquarter functions they often play within their groups. They can therefore be passive in terms of taking on roles as local network co-ordinators or intermediaries. This implies the need for the public sector to take on a role as a network intermediary, broker or "dealmaker" across large firms, start-ups, scale-ups, SMEs and HEIs.

While the regional government has started to support more frequent networking events, they often fail to develop into concrete actions or agreements between stakeholders and stakeholders can become lost in the system given the large number of different external providers. Large enterprises could become important anchors for networking events and activities by offering them co-ordination support, while existing networking platforms for start-ups can be made more inclusive of large firms. 
Box 1.3. Recommendations on embedding large firms in the local entrepreneurship ecosystem

1. Communicate and develop a value proposition based on the skills, R\&D and startup activity of the region in order to attract and expand FDI with greater R\&D activity, knowledge intensity and propensity to engage with regional entrepreneurship and innovation.

2. Steer FDI towards the periphery of the region, especially where there are existing smart specialisation strengths there, both by appropriate FDI marketing efforts and efforts to build local capabilities.

3. Approach large firms with a view to engaging them in investments, mentoring and financing of business accelerators and incubators and involving them in the activities of the Centres of Entrepreneurship.

4. Strengthen intermediary organisations as network hubs between large enterprises, start-ups, scale-ups, SMEs, HEIs and research organisations in the local entrepreneurship ecosystem including incubators, the Centre for Creativity and the cluster organisations. Ensure co-ordination and coherence across the network intermediaries and outcomes for participants. 


\section{References}

Asheim, B.T., M. Grillitsch, and M. Trippl. (2017a), "Smart Specialisation as an Innovation-driven Strategy for Economic Diversification”, in S. Radosevic et al. (eds.) Advances in the Theory and Practice of Smart Specialisation, Amsterdam: Elsevier Science Publishers.

Di Berardino, C., D. D'Ingiullo and G. Onesti (2017), “International Skilled-Migration and Regional Growth in Poland", Journal of Applied Economic Sciences, Vol. 3/49, pp. 863-874.

Domański, B. (2003), "Industrial Change and Foreign Direct Investment in the Postsocialist Economy", European Urban and Regional Studies, Vol. 10/2, pp. 99-118.

Jones Lang LaSalle (2017), Warsaw Office Market 2016, http://absl.pl/wpcontent/uploads/2016/02/Warsaw-Office-Market-2016.pdf.

Marinelli, E., J. Edwards and C. Mironov (2017), "Higher Education for Smart Specialisation: The case of North East Romania", JRC Technical Reports, Luxembourg, Publications Office of the European Union. doi: $10.2760 / 598009$

OECD (2016), Employment and Skills Strategies in Poland, OECD Reviews on Local Job Creation, OECD Publishing, Paris, http://dx.doi.org/10.1787/9789264256521-en.

Salameh, N., M. Rauch, and J. Ulrich (2011), "Business R\&D in Poland - The Role of the Economic Structure", World Economy Research Institute Working Paper No 307, World Economy Research Institute, Warsaw School of Economics, Warsaw. 


\section{The Mazowieckie entrepreneurship ecosystem and smart specialisation policy}

This section discusses the key characteristics of the local entrepreneurship ecosystem as a foundation for entrepreneurship and emerging industries, covering the dimensions of demand, skills, enterprise networks and business support policies. It also examines the smart specialisation policy of the region and its selected smart specialisations.

\subsection{Introduction}

Mazowieckie is located in the central-eastern part of Poland on the Mazowieckie Lowland. It is the largest and most populated region of Poland. It is also the most economically developed, producing approximately $22 \%$ of national gross domestic product (GDP). The main administrative centre is Warsaw, the capital of Poland, which produces nearly $60 \%$ of the region's GDP. Mazowieckie also has the largest rural population in Poland, with one in four people working in agriculture. ${ }^{1}$ A general description of the regional economy of the region is given in Table 2.1 .

Table 2.1. Description of the Mazowieckie economy

Data relate to end 2015

\begin{tabular}{|l|c|c|c|}
\hline \multicolumn{1}{|c|}{ Specification } & Mazowieckie & Poland & $\begin{array}{c}\text { Mazowieckie's share of } \\
\text { the national total }\end{array}$ \\
\hline \multicolumn{3}{|c|}{ Market potential } \\
\hline GDP per capita, 2014 (PLN) & 71659 & 44686 & - \\
\hline Population (31 December 2016) & 5365898 & 38432992 & $14.0 \%$ \\
\hline $\begin{array}{l}\text { Graduates of higher education } \\
\text { institutions, 2016 (persons) }\end{array}$ & 66625 & 364399 & $8.3 \%$ \\
\hline
\end{tabular}

\footnotetext{
${ }^{1}$ Mazowieckie Profile 2017, Polish Investment and Trade Agency, https://www.paih.gov.pl/index/?id=6ce1861d265248f9c9dd2ed2f88dbdf9
} 


\begin{tabular}{|c|c|c|c|}
\hline $\begin{array}{l}\text { Graduates of secondary schools, } 2016 \\
\text { (persons) }\end{array}$ & 37562 & 268502 & $14.0 \%$ \\
\hline $\begin{array}{l}\text { Number of employees, } 2016 \text { (persons, } \\
\text { thousands) }\end{array}$ & 2457 & 16197 & $15.2 \%$ \\
\hline $\begin{array}{l}\text { Structure of employees, } 2016 \\
\text { Agricultural sector } \\
\text { Industrial sector } \\
\text { Service sector }\end{array}$ & $\begin{array}{r}10.8 \% \\
23 \% \\
66.1 \%\end{array}$ & $\begin{array}{l}10.6 \% \\
31.4 \% \\
58.0 \%\end{array}$ & \\
\hline \multicolumn{4}{|c|}{ Capital expenditures and capital of companies with foreign capital in the region } \\
\hline $\begin{array}{l}\text { Investment expenditures, } 2015 \\
\text { (PLN million) }\end{array}$ & 39346.5 & 83788.9 & $47.0 \%$ \\
\hline $\begin{array}{l}\begin{array}{l}\text { Capital of companies, } 2015 \text { (PLN } \\
\text { million) }\end{array} \\
\end{array}$ & 96592.0 & 203897.8 & $47.4 \%$ \\
\hline
\end{tabular}

\subsection{Demand}

Mazowieckie as a whole has the highest GDP per capita of the Polish regions. This amounted to $131 \%$ of the national average in 2016; i.e. PLN 134044 compared with a Polish average of PLN 102417 (OECD Regional Statistics database). GDP growth in the region in 2004-16 amounted to 203\%, with the average for Poland being $185 \%$. Within the region, GDP per head in 2015 was $119 \%$ of the region's average in the city of Warsaw compared with 88\% in Warsaw West Poviat (PLN 117 885), 75\% in Warsaw East Poviat and $62 \%$ in Radomski Poviat (OECD Regional Statistics database). In addition to strong internal demand for products and services, Mazowieckie has good access to international markets, with a share of $18.2 \%$ of total Polish export value in 2012. Warsaw was responsible for 51\% of the region's exports in 2012 (Central Statistical Office).

\subsection{Skills and talent}

Mazowieckie has a relatively large population. In 2016, there were some 5365898 inhabitants, accounting for $13.9 \%$ of the population of Poland. Some $65 \%$ of the regional population are in urban areas, and the remaining 35\% in rural areas. The urban areas account for $86 \%$ of employment. The regional population is forecast to continue to grow 
modestly in the next decade. ${ }^{2}$ The registered unemployment rate in the region was $5.9 \%$ in September 2017, compared to $6.8 \%$ in Poland. ${ }^{3}$ The average monthly gross wages in the enterprise sector in the first half of 2017 amounted to PLN 5349.50 , or $131 \%$ of the average remuneration in Poland. ${ }^{4}$

\subsection{Access to finance}

Outside the commercial banking system, the Mazowieckie Regional Loan Fund and Mazowieckie Loan Guarantee Fund are both operating in the region to support access of SMEs and entrepreneurs to finance. In addition, the National Capital Fund (BGK Bank) offers loan finance. There are also a number of grants available for the development of entrepreneurship from the Regional Operational Programme and National Operation Programmes. However, SMEs and entrepreneurs in the region still report difficulties in access to finance, including both debt and equity.

\subsection{Knowledge}

Mazowieckie has very strong capabilities in the generation of knowledge. Mazowieckie has the highest intensity of $R \& D$ expenditure of all Polish regions and the highest proportion of employees in $R \& D$ occupations. More than a third of $R \& D$ employees in the country are employed in Mazowieckie. R\&D is carried out in almost all industry fields in the region, and there is significant employment in medium-high-tech and high-tech manufacturing sectors in the region. However, $R \& D$ expenditure is heavily concentrated in the services sector. Indeed, Mazowieckie accounts for around $75 \%$ of total R\&D expenditure in the services sector in Poland.

Mazowieckie also hosts the renowned University of Warsaw, the Warsaw University of Technology (one of the largest in Central and Eastern Europe), the Medical University of Warsaw (which is the largest and one of the most prominent medical schools in Poland), the Warsaw School of Economics (the oldest and most prestigious economic school in the country) and the Warsaw University of Life Sciences (the largest agricultural university of Poland), among others.

\subsection{Networks}

Enterprise networking is not a strong feature of the region beyond supply chain collaborations between suppliers and customers. This reflects passivity of enterprises towards networking and a lack of trust and social capital, which is a wider problem in

\footnotetext{
${ }^{2}$ Based on: Regional Operational Programme of the Mazowieckie Voivodeship for the years 2014-20, the Board of the Mazowieckie Voivodeship, Warsaw, 12 February 2015.

${ }^{3}$ Unemployed and unemployment rate by voivodeships, sub-regions and powiats (as at the end of September 2017) of the Central Statistical Office.

${ }^{4}$ The following data based on: Statistical Bulletin of the Mazowieckie Voivodeship from the first quarter of 2017 and Statistical Bulletin of 2017, www.stat.gov.pl (07/11/2017).
} 
Poland (Dzialek, 2009). Greater enterprise networking could be favoured to reinforce cluster and network initiatives.

A number of cluster initiatives have been established in the region, across a wide range of industries. Most are in Warsaw, although a significant minority is located in other cities of the region (Radom, Pniewy, Skierniewice, Płock). They include ${ }^{5}$ :

- Mazowiecki Cluster of Innovative Photonics (optoelectronics).

- Mazowieckie Aviation Cluster and General Aviation (aviation).

- Construction Cluster (construction).

- Cluster of Animal Protection and Monitoring, Co-operative Relations "Migracje.NET" (protection and monitoring of aquatic and terrestrial animals).

- Mazowieckie Space Cluster (space technologies and satellite techniques).

- Cluster of Polish Furniture Manufacturers (furniture industry).

- SpediGo Polish Group cluster (transport services).

In 2011 an overarching organisation was also established - Mazovia Multicluster - which gathers and supports the most innovative and active clusters in the region.

However, there are a number of weaknesses associated with current cluster functioning. Most of the cluster organisations are still at an early stage of development, and some are not strongly active. There is no joint management model for clusters and it is not standard for research organisations to be included in the cluster organisations. In addition, there are many cluster initiatives, which limits the possibility of implementing larger projects and weakens the visibility of individual clusters. This suggests that an important policy task is to create tools for the integration of clusters using financial and legal incentives to stimulate co-operation.

\subsection{Business support system}

There is significant regional business support provided by the regional government of Mazowieckie. The main initiatives are discussed below.

\section{Incubators}

There are six business incubators in the region, five in Warsaw and one in Radom. There are also ten academic business incubators in the region supporting entrepreneurship from HEIs, including eight in Warsaw and two in Plock. These incubators play an important role in supporting innovative entrepreneurship, focusing primarily on enterprises with high development potential.

\section{Innovation and entrepreneurship centres}

Mazowieckie had 92 innovation and entrepreneurship centres in 2012, only the second ranked region in Poland on this measure despite its large size. An average of 7338

\footnotetext{
${ }^{5}$ Regional Innovation Strategy for Mazowieckie to 2020, Innovation Support System and Smart Specialisation of the Region, Warsaw 2015, Annex to Resolution No. 23/15 of the Mazowieckie Voivodeship Assembly of 16 March 2015.
} 
companies was served by each centre, the greatest number among the Polish regions. This may indicate that access to centres is constrained.

\section{Special Economic Zones}

Five branches of special economic zones are located in the region, in Łódzka, Starachowicka, Suwalska, Tarnobrzeska and Warmińsko-Mazurska. Investors in these zones can obtain a corporate income tax exemption generally worth $35-55 \%$ of the value of the investment, with small and medium sized enterprises (SMEs) eligible for the higher subsidy rate. ${ }^{6}$

\section{Science and technology parks}

\section{Ptock Industrial and Technological Park}

Plock Industrial and Technological Park (PPPT) is located in the north-western part of Mazowieckie, about $100 \mathrm{~km}$ from Warsaw, Toruń and Łódź. It covers an area of over 200 hectares including three related components: an industrial park, a technology park and a science and research park. It is a joint venture of the local authorities of the City of Płock and a public company, PKN ORLEN S.A., appointed to create attractive conditions for the development of enterprises. Key residents of the park include Basell Orlen Polyolefins Ltd. and PCC Rokita Joint-Stock Company in chemical technologies as well as other enterprises and research organisations in chemical fields, environmental protection, waste management and recycling, logistics, financial services, and R\&D, and IT and telecommunications. The park includes a number of facilities for start-ups and scale-ups, including a Corporate Services Centre and Central Laboratory. ${ }^{7}$

\section{Science and Technology Park ŚWIERK (PNT)}

This park, operated by the National Centre for Nuclear Research, focuses on nuclear technologies. This includes particle accelerators, radiation detectors and detection electronics, information technology, nanotechnology, new materials, medical technologies, nuclear and alternative energy, isotopes, nuclear fuels and environmental protection although it is also open to other fields.

It supports knowledge exchange between scientific and research institutions and existing and new enterprises in a number of ways, including offering laboratory space, scientific supervision for research projects implemented in the park and support for negotiating technology transfer agreements. It also supports innovative start-ups and scale-ups with the possibility of incubation and investment support on preferential terms. It fosters innovation co-operation among companies on the park by providing them with collaborative settings and close proximity. ${ }^{8}$

\footnotetext{
${ }^{6}$ More on the rules of public aid: http://www.paih.gov.pl/strefa_inwestora/zachety_inwestycyjne_w_sse

${ }^{7}$ More information at http://www.pppt.pl/PL/Strony/default.aspx

${ }^{8}$ More information: http://pnt.ncbj.gov.pl
} 
Mazowieckie Science and Technology Park - Co-operative Park in Płońsk (MPNT)

This park focuses on supporting the agri-food sector in the region. It focuses on the development of biotechnology, renewable energy sources, innovations in agriculture, and the strengthening of clusters in agri-food, biotechnology, ecology, renewable energy sources and informatics.

The park co-operates with entrepreneurs, scientists and regional public institutions to achieve common goals and implement joint projects.

The park's activities are:

- Comprehensive support and promotion of members' activities.

- Linking science with practice by supporting knowledge transfer.

- Helping to create and develop enterprises (especially those in rural areas) who want to operate on the basis of modern ideas and solutions.

- An initiative of partnership co-operation between entities in the country and abroad.

- Activating business operations, creating cluster initiatives and operational groups.

- Promoting and popularising what is associated with innovation. ${ }^{9}$

\subsection{Overview of the pillars of the local entrepreneurship ecosystem}

Analysis has been undertaken for all the regions of Poland to examine their relative strengths and weaknesses on 10 ecosystem pillars using standardised scores on key variables. Annex A sets out the indicators used. On each pillar, the data have been normalised (the value of the variable minus the mean, divided by the standard variation) and standardised to give scores relative to 1 . Table 2.2 shows the scores and Table 2.3 shows the rankings of the regions on each pillar.

Table 2.2. Local entrepreneurship ecosystem indicators by ecosystem pillar and Polish region - index values

\begin{tabular}{llllllllllll}
\hline & $\begin{array}{l}\text { Formal } \\
\text { institut } \\
\text { ions }\end{array}$ & $\begin{array}{l}\text { Entreprene } \\
\text { urship } \\
\text { culture }\end{array}$ & $\begin{array}{l}\text { Physical } \\
\text { infrastru } \\
\text { cture }\end{array}$ & $\begin{array}{l}\text { Dema } \\
\text { nd }\end{array}$ & $\begin{array}{l}\text { Netwo } \\
\text { rks }\end{array}$ & $\begin{array}{l}\text { Tale } \\
\text { nt }\end{array}$ & $\begin{array}{l}\text { Fina } \\
\text { nce }\end{array}$ & $\begin{array}{l}\text { New } \\
\text { knowle } \\
\text { dge }\end{array}$ & $\begin{array}{l}\text { Interme } \\
\text { diate } \\
\text { services }\end{array}$ & $\begin{array}{l}\text { Leader } \\
\text { ship }\end{array}$ & $\begin{array}{l}\text { Over } \\
\text { all }\end{array}$ \\
\hline Dolnoslaskie & 0.70 & 1.15 & 1.14 & 1.12 & 0.92 & 1.0 & 1.31 & 1.03 & 1.19 & $\begin{array}{r}1.05 \\
8\end{array}$ \\
& & & & & & 8 & & & & $\mathbf{1 0 . 6}$ \\
$\mathbf{8}$
\end{tabular}

\footnotetext{
${ }^{9}$ More at: http://www.mpnt.pl/pl/about
} 


\begin{tabular}{|c|c|c|c|c|c|c|c|c|c|c|c|}
\hline Lubuskie & 1.16 & 1.07 & 0.97 & 0.86 & 0.87 & $\begin{array}{l}0.8 \\
5\end{array}$ & 0.84 & 0.81 & 1.01 & 0.83 & 9.26 \\
\hline Lodzkie & 0.84 & 0.96 & 1.02 & 1.01 & 0.96 & $\begin{array}{l}0.9 \\
9\end{array}$ & 1.20 & 1.04 & 0.91 & 0.97 & 9.91 \\
\hline Malopolskie & 1.04 & 1.11 & 1.12 & 1.07 & 0.87 & $\begin{array}{l}1.0 \\
9\end{array}$ & 0.88 & 1.39 & 1.00 & 1.14 & $\begin{array}{r}10.7 \\
1\end{array}$ \\
\hline Mazowieckie & 0.80 & 1.44 & 1.13 & 1.56 & 0.84 & $\begin{array}{l}1.6 \\
2\end{array}$ & 0.79 & 1.52 & 1.54 & 1.56 & $\begin{array}{r}12.7 \\
9\end{array}$ \\
\hline Opolskie & 1.33 & 0.75 & 1.06 & 0.84 & 1.08 & $\begin{array}{l}0.8 \\
7\end{array}$ & 1.05 & 0.79 & 0.89 & 0.90 & 9.56 \\
\hline Podkarpackie & 0.83 & 0.80 & 0.94 & 0.90 & 1.43 & $\begin{array}{l}0.9 \\
1\end{array}$ & 0.94 & 1.34 & 0.83 & 1.10 & $\begin{array}{r}10.0 \\
1\end{array}$ \\
\hline Podlaskie & 1.19 & 0.81 & 0.81 & 0.93 & 0.99 & $\begin{array}{l}1.1 \\
1\end{array}$ & 1.01 & 0.97 & 0.95 & 0.84 & 9.52 \\
\hline Pomorskie & 1.17 & 1.27 & 1.01 & 1.00 & 0.93 & $\begin{array}{l}1.0 \\
5\end{array}$ & 0.98 & 1.21 & 1.10 & 1.00 & $\begin{array}{r}10.7 \\
4\end{array}$ \\
\hline Slaskie & 0.70 & 0.89 & 1.37 & 1.23 & 0.93 & $\begin{array}{l}0.9 \\
7\end{array}$ & 0.86 & 1.01 & 0.99 & 1.12 & $\begin{array}{r}10.0 \\
8\end{array}$ \\
\hline $\begin{array}{l}\text { Swietokryzski } \\
\text { e }\end{array}$ & 0.89 & 0.86 & 0.87 & 0.84 & 0.98 & $\begin{array}{l}1.0 \\
1\end{array}$ & 1.48 & 0.86 & 0.74 & 0.87 & 9.40 \\
\hline $\begin{array}{l}\text { Warminsko- } \\
\text { Mazurskie }\end{array}$ & 1.10 & 0.85 & 0.84 & 0.85 & 0.84 & $\begin{array}{l}0.8 \\
1\end{array}$ & 0.96 & 0.87 & 1.12 & 0.80 & 9.02 \\
\hline Wielkopolskie & 0.95 & 1.12 & 1.02 & 1.15 & 0.89 & $\begin{array}{l}0.9 \\
5\end{array}$ & 0.82 & 1.01 & 0.73 & 1.17 & 9.81 \\
\hline $\begin{array}{l}\text { Zachodniopo } \\
\text { morskie }\end{array}$ & 1.06 & 1.20 & 0.874 & 0.91 & 1.08 & $\begin{array}{l}0.9 \\
2\end{array}$ & 1.18 & 0.83 & 1.19 & 0.83 & $\begin{array}{r}10.0 \\
8\end{array}$ \\
\hline
\end{tabular}


Table 2.3. Local entrepreneurship ecosystem indicators by ecosystem pillar and Polish region - rankings

\begin{tabular}{|c|c|c|c|c|c|c|c|c|c|c|c|}
\hline & $\begin{array}{l}\text { Formal } \\
\text { institut } \\
\text { ions }\end{array}$ & $\begin{array}{l}\text { Entreprene } \\
\text { urship } \\
\text { culture }\end{array}$ & $\begin{array}{l}\text { Physical } \\
\text { infrastru } \\
\text { cture }\end{array}$ & $\begin{array}{l}\text { Dema } \\
\text { nd }\end{array}$ & $\begin{array}{l}\text { Netwo } \\
\text { rks }\end{array}$ & $\begin{array}{l}\text { Tale } \\
\text { nt }\end{array}$ & $\begin{array}{l}\text { Fina } \\
\text { nce }\end{array}$ & $\begin{array}{l}\text { New } \\
\text { knowle } \\
\text { dge }\end{array}$ & $\begin{array}{l}\text { Interme } \\
\text { diate } \\
\text { services }\end{array}$ & $\begin{array}{l}\text { Leader } \\
\text { ship }\end{array}$ & $\begin{array}{l}\text { Over } \\
\text { all }\end{array}$ \\
\hline Dolnoslaskie & 16 & 4 & 2 & 4 & 10 & 4 & 2 & 6 & 2 & $\overline{6}$ & 4 \\
\hline $\begin{array}{l}\text { Kujawsko- } \\
\text { Pomorskie }\end{array}$ & 2 & 9 & 9 & 8 & 14 & 16 & 10 & 13 & 13 & 9 & 15 \\
\hline Lubelskie & 10 & 15 & 15 & 11 & 1 & 5 & 16 & 9 & 9 & 11 & 10 \\
\hline Lubuskie & 5 & 7 & 10 & 12 & 12 & 14 & 13 & 15 & 6 & 15 & 14 \\
\hline Lodzkie & 12 & 8 & 6 & 6 & 7 & 8 & 3 & 5 & 11 & 8 & 8 \\
\hline Malopolskie & 8 & 6 & 4 & 5 & 12 & 3 & 11 & 2 & 7 & 3 & 3 \\
\hline Mazowieckie & 14 & 1 & 3 & 1 & 16 & 1 & 15 & 1 & 1 & 1 & 1 \\
\hline Opolskie & 1 & 16 & 5 & 14 & 3 & 13 & 5 & 16 & 12 & 10 & 11 \\
\hline Podkarpackie & 13 & 14 & 11 & 10 & 2 & 12 & 9 & 3 & 14 & 5 & 7 \\
\hline Podlaskie & 3 & 13 & 16 & 16 & 5 & 2 & 6 & 10 & 10 & 13 & 12 \\
\hline Pomorskie & 4 & 2 & 8 & 7 & 8 & 6 & 7 & 4 & 5 & 7 & 2 \\
\hline Slaskie & 15 & 10 & 1 & 2 & 8 & 9 & 12 & 8 & 8 & 4 & 6 \\
\hline $\begin{array}{l}\text { Swietokryzski } \\
\text { e }\end{array}$ & 11 & 11 & 13 & 15 & 6 & 7 & 1 & 12 & 15 & 12 & 13 \\
\hline $\begin{array}{l}\text { Warminsko- } \\
\text { Mazurskie }\end{array}$ & 6 & 12 & 14 & 13 & 15 & 15 & 8 & 11 & 4 & 16 & 16 \\
\hline Wielkopolskie & 9 & 5 & 7 & 3 & 11 & 10 & 14 & 7 & 16 & 2 & 9 \\
\hline $\begin{array}{l}\text { Zachodniopo } \\
\text { morskie }\end{array}$ & 7 & 3 & 12 & 9 & 4 & 11 & 4 & 14 & 2 & 14 & 5 \\
\hline
\end{tabular}

Source: See Annex A for data sources

Mazowickie ranks very highly overall. Compared with other Polish regions it is the highest ranked region for its overall local entrepreneurship ecosystem. However, its scores are uneven across different local entrepreneurship ecosystem pillars. It is the top ranked region in Poland in the areas of entrepreneurship culture, demand, talent and skills, new knowledge, intermediate services and leadership. It also ranks very well on infrastructure. However, it has a relatively weak performance on three local entrepreneurship ecosystem pillars, namely formal institutions, networks and access to finance. This suggests that policy efforts in the region need to be strongly focused on improving institutions in the 
form of trust in government, networks in terms of participation in clusters and access to finance in terms of SME access to loans.

\subsection{The regional development policy approach}

\section{The regional economic development strategy}

The economic development policy of the regional government is set out in the Development Strategy of the Mazowieckie Region to 2030, prepared by the Mazowieckie Regional Planning Office (MBPR). ${ }^{10}$

The main priority objective of the Development Strategy is territorial cohesion. This is to be understood as both developing the periphery of the region to reduce development disparities within the region (105 of the 500 poorest communes in Poland are in the region) and strengthening the Warsaw Metropolitan Area (WMA) to become one of the leading metropolises in the European Union.

The strategy also includes three strategic objectives:

- Increased competitiveness of the region through business development and transfer and use of new technologies.

- Improvement of territorial accessibility and territorial cohesion, shaping the quality of life.

- Use of human and social capital to create a modern economy.

These policy objectives are to be achieved by promoting the diffusion of innovation from the WMA to the periphery and by developing export-oriented production in advanced and medium-advanced technology industries in the region. In order to promote balanced regional development technology development opportunities in the agri-food and food processing industries in the periphery are expect to receive a particular stimulus.

The Strategy foresees actions in the following directions:

- Creating conditions for generating and absorbing innovations.

- Production development: creating conditions that are friendly to investors and entrepreneurs.

- Supporting the creation and development of production enterprises.

- Economic internationalisation.

- Creating conditions for increasing non-agricultural investments - mainly in the agri-food industry (in order to diversify production in rural areas).

- Raising awareness of companies about business model and product innovation.

${ }^{10}$ Development Strategy of the Mazowieckie Voivodeship to 2030, Innovative Mazowieckie, Annex to Resolution No. 158/13 of the Mazowieckie Regional Assembly of 28 October 2013. 
Actions to support this agenda can be financed in particular through the European Structural and Investment Funds, managed through Regional Operational Programme (ROP) for Mazowieckie. ${ }^{11}$

\section{The regional smart specialisation policy}

An important element of the regional economic development strategy is the Regional Innovation Strategy (RIS), which guides policy expenditures on entrepreneurship and innovation. The regional government adopted a first RIS for Mazowieckie in 2008. This focused on creating a supportive innovation system across a range of sectors, including by building and consolidating a network of co-operative links and creating sustainable innovation tools.

From the second half of 2012, work was undertaken to develop a second RIS for the EU's Multiannual Financial Framework for 2014-2020, this time emphasising investments in smart specialisations for the region, following new EU smart specialisation guidance. In line with the EU guidance, the process of establishing the smart specialisation strategy involved an industry diagnosis and a stakeholder consultation process with research and business. The regional government adopted the resulting smart specialisation strategy in 2015. ${ }^{12}$ The actions are implemented through the Regional Operational Programme 201420.

Mazowieckie has a diversified regional economy and research centres in a range of fields. This provides a number of potential smart specialisations for the region. Approximately $66 \%$ of its employment is in services (concentrated particularly in Warsaw, the subregional centres of Ostroleka, Plock, Siedlce and the sub-regions of Piaseczyński and Pruszkowski), $23 \%$ in the industrial sectors and $11 \%$ in agriculture, and the region has specialisations in all of these broad industry groups. In particular, the region has both employment concentrations and research strengths in agricultural production, refinery and petrochemical industries, transport and advanced technologies, financial intermediation, business services, telecommunications and education. ${ }^{13}$ Cluster organisations have been set up in the region that cover a number of these specialisations.

Given the diverse industry development opportunities, the regional government chose to focus on smart specialisations that can act as contact points across different businesses, technologies and processes and that respond to the needs of residents and fit into global trends. As a result, four areas of regional smart specialisation were selected, as shown in Table 2.4. ${ }^{14}$

\footnotetext{
11 See: Regional Operational Programme of the Mazowieckie Voivodeship 2014-20, the Board of the Mazowieckie Voivodeship, Warsaw, 12 February 2015

12 Regional Innovation Strategy for Mazowieckie to 2020, Innovation Support System and Smart Specialisation of the Region, Warsaw 2015, Annex to Resolution No. 23/15 of the Mazowieckie Regional Assembly of 16 March 2015

${ }^{13}$ Based on: Investment attractiveness of the regions 2017, Mazowieckie Voivodeship, Report prepared for the Polish Investment and Trade
Agency at the Institute of Enterprises of the Warsaw School of Economics, Warsaw, November 2017.

${ }^{14}$ Regional Innovation Strategy for Mazowieckie to 2020, Innovation Support System and Smart Specialisation of the Region, Warsaw 2015, Annex to Resolution No. 23/15 of the Mazowieckie Voivodeship Assembly of 16 March 2015.
} 
Table 2.4. Mazowieckie smart specialisation strategy - the selected regional specialisations

\begin{tabular}{ll}
\hline \multicolumn{1}{c}{ Specialisation } & \multicolumn{1}{c}{ Description of specialisation } \\
\hline Safe Food & $\begin{array}{l}\text { Actions increasing the availability and enabling the development of high-quality food } \\
\text { products, consistent with the idea of sustainable development, safe for both the final } \\
\text { recipient and the environment throughout the production and distribution cycle }\end{array}$ \\
Intelligent Management Systems & $\begin{array}{l}\text { Infrastructure and process solutions characterised by a high degree of adaptability, } \\
\text { leading to increased automation and enabling effective monitoring of processes related } \\
\text { to economic activity, increasing the effectiveness of raw materials and energy and } \\
\text { improving quality of life, also in the context of human safety. }\end{array}$ \\
Modern Services for Business & $\begin{array}{l}\text { Mechanisms for supporting business activity; customised services tailored to individual } \\
\text { needs, providing capital, infrastructure and knowledge necessary to develop and increase } \\
\text { the innovative activity of enterprises }\end{array}$ \\
High Quality of Life & $\begin{array}{l}\text { Technological and organisational solutions used to provide social services, in particular } \\
\text { in the areas of education, health, safety, work and leisure time; actions aimed at } \\
\text { stimulating social innovations, development of social capital and counteracting the } \\
\text { negative effects of the developmental polarisation of the region }\end{array}$ \\
\hline
\end{tabular}

Source: Regional Innovation Strategy for Mazowieckie to 2020, Innovation Support System and Smart Specialisation of the Region, Warsaw 2015, Annex to Resolution No. 23/15 of the Mazowieckie Voivodeship Assembly of 16 March 2015.

A number of issues can be identified with this choice of smart specialisation areas, in part reflecting concerns about lack of prioritisation in regional smart specialisation strategies more generally:

1. The smart specialisations are broad, whereas smart specialisation strategies should generally aim to prioritise and steer policy efforts towards a limited number of specific industry development opportunities. There are four smart specialisations, which leaves some room for narrowing down to better prioritise. However, the main issue is many of the smart specialisation areas are broad enough to cover a large number of different types of sector focus. In particular, intelligent management systems and modern services for business appear to be open to support business in any field of activity.

2. The specialisations represent a mix of industry development opportunities (safe food) and activities aimed at reaching broader societal end goals (improving quality of life).

3. Two of the specialisations (intelligent management systems and modern services for business) seem to focus on supporting methods of improving business performance generally rather than real attempts to build new industries providing products and services in these areas.

Overall, the picture is one of a very broad and mixed smart specialisation strategy rather than one prioritising a small number of specific industry path development opportunities. One reason for this may be that the EDP did not involve stakeholders in an effective way. In particular, some parts of the business sector, and especially SMEs, did not actively participate in the initial EDP. Their involvement could help make the future path development directions more specific, based on more specific information about technology and market opportunities.

A key challenge for the region now will therefore be to renew the EDP to go beyond the broad specialisations identified in the RIS3 strategy in order to identify the more specific and narrower $R \& D$, technological and industrial strengths of the region that can be used to develop diversified specialisations. In other words, the four RIS3 priorities have to be made 
more specific and concrete. To achieve this the EDP needs to be seen as a continuous process involving all the key stakeholders from research, business and government in defining the diversification opportunities, the policy instruments to be employed, and the organisational and institutional adaptations needed.

\section{References}

Dzialek, J. (2009), "Social Capital and Economic Growth in Polish Regions", University of Munich MPRA Paper 18287, Munich, https://mpra.ub.uni-muenchen.de/18287/1/MPRA_paper_18287.pdf 


\section{Smart specialisation and industry path development}

This section examines regional pre-conditions for industry path development, and proposes new path development opportunities to be pursued by smart specialisation policy. This can be used as the basis of a renewed entrepreneurial discovery process that seeks to make the region's existing smart specialisations more narrow and specific.

\subsection{Adapting to regional pre-conditions in industry path development strategies}

\section{Assessment framework}

The OECD local entrepreneurship ecosystem and emerging industries project adopts a framework for assessing the potential for industry path development as set out in Annex A.

The framework is based on the understanding that regional economies can evolve along various industrial transition pathways with the different opportunities affected by the preconditions of the region. It is important for policymakers in Mazowieckie to understand the possibilities in their region with respect to the region's pre-conditions.

In general, the main path development opportunities for a region are characterised below (see Asheim et al., 2017a):

- Path upgrading. This implies changing the direction of an existing regional industrial path through renewal, climbing global production networks (GPNs), or niche development.

- Path diversification. This can involve related diversification, i.e. the redeployment of existing assets into related fields and industries. Alternatively, it can involve unrelated diversification, i.e. firms moving into new industries by combining their existing knowledge base with new, unrelated knowledge.

- Path emergence. This involves the establishment of industries that are new to the region and unrelated to its existing industries. It can occur through importation of existing industries from elsewhere, for example through inward investment, attraction of mobile talent or innovation partnerships with distant sources. It can also involve new path creation, i.e. creation of new industries based on new technological and organisational knowledge, for example generated in large firms and higher education institutions (HEIs) in the region.

Traditional regional development approaches have largely focused on path upgrading. These approaches offer short and medium-term opportunities for productivity growth. However, strategies for new path development through diversification and path emergence promote more diversity in a region and offer greater opportunities for long-term regional 
productivity growth. While new path development is deserving of particular attention, an optimal strategy for a region is likely to involve a combination of both path upgrading for short and medium-term development and path diversification and path emergence for longer-term development.

The framework also identifies two key dimensions of the regional pre-conditions for industry path development influencing policy options for path development, namely:

- Industry diversification and innovation capacity, in terms of the extent to which the economy is specialised or diversified and the extent to which the region has high or low innovation capacity.

- Innovation system differentiation, in terms of the sophistication of actors, networks and institutions for innovation in the region.

Different types of industry path development opportunities are favoured by different types of pre-conditions. Notably, regions with high industry diversification and innovation capacity and high system differentiation are likely to have more success with strategies for new path development (Related Diversification, Unrelated Diversification or Path Creation). Regions that are weaker on these dimensions are likely to have more success with more short and medium-term forms of new path development such as various forms of path upgrading strategies (Climbing GPN, Renewal, Niche Development) or Path Importation.

Mazowieckie's performance on these regional pre-conditions dimensions is assessed below and the implications for industry transition policy options in the region.

\section{Overview of the regional industry base}

\section{Centre (Warsaw)}

Mazowieckie has a population of 5.4 million. At its centre is Warsaw, which has a population comprising 1.764 million in the city of Warsaw or 2.57 million inhabitants in the conurbation (Central Statistical Office, 2017). Warsaw has the highest income per capita of Central and Eastern European country capitals. It ranked as a "moderate innovator" in the EU's 2017 Regional Innovation Scoreboard.

Warsaw is classed as an "alpha city" by the Globalisation and World Cities study group from Loughborough University, i.e. as "a major global city that links economic regions into the world economy", alongside cities such as Sydney, Istanbul, Amsterdam and Seoul. It is considered to be in $58^{\text {th }}$ place on the 2017 Global City Ranking (2017), and $31^{\text {st }}$ on the Future Global City Outlook (A. T. Kearney, 2017). Warsaw is shaped by advanced service industries rather than by manufacturing. It is the main hub for financial services within Central and Eastern Europe. In particular the Śródmieście district is not only characterised by governmental and related organisations typical of a capital city, but also by a stock market (Giełda Papierów Wartościowych w Warszawie), established in 1991. Warsaw is a leading location for FDI in Central and Eastern Europe. Investors such as Goldman Sachs, JP Morgan, Citi Group, UBS and Credit Suisse recently have invested in this financial quarter, and the former city hall now hosts a range of financial institutions.

The city is also a major centre for IT. Although Poland entered the path of IT development with a slight delay (compared to the IT sector globally), since the early 2000s significant dynamics have been observed, particularly in e-commerce and e-government (Dominiak, 2011). Warsaw today functions as a back-office for international banks, financial service 
providers and information technology developers. Warsaw has been classified as the $25^{\text {th }}$ best global investment location for Business Process Outsourcing (BPO) and Shared Service Centres (SSC), with about 36700 employees working in 155 centres of BPO/SSC, information technology outsourcing (ITO) and R\&D (Jones Lang LaSalle, 2017). $\mathrm{BPO} / \mathrm{SSC} / \mathrm{ITO}$ are based on, and have created, a basis for further upscaling and entrepreneurial dynamics.

Beyond finance and IT, education and creativity is another related variety in Warsaw. Warsaw has spawned internationally renowned authors, film-makers, designers etc. and has experienced a gold-rush mood in fields of creativeness, inspiration and inventiveness (Kasprzak, 2015).

In terms of R\&D, Warsaw hosts the four leading Polish universities - University of Warsaw, Warsaw University of Technology, Warsaw School of Economics, and Warsaw University of Life Sciences. Warsaw's companies profit from a comprehensive knowledge base with the whole spectrum of basic research, experience-based and practical, collaborative and inventive-artistic competencies (see Asheim, 2007).

\section{The periphery}

Surrounding Warsaw, there is initially an urban sprawl, i.e. regions with a high dynamic of employment and housing, and beyond smaller cities and agrarian regions.

Fruit production is located mainly in the south of Mazowieckie. Horticulture shapes the landscape along the Vistula River and the areas around the capital. Dairy farms are primarily located in the North, poultry in the Northwest. Apple production is also important in the region; the tradition of fruit growing in the Grójec region of Mazowieckie dates back to the $16^{\text {th }}$ century, with skilled and well-trained growers (Wójcik and Taczyk, 2017). Mazowieckie's apple production offers a potential strategic base for rural development, generating about half the apple production in Poland, with related activities around the growing of apples, including marketing campaigns.

Further important sectors in the periphery are biomedicine, chemicals, metal working, mechanics, optoelectronics and photovoltaic industries. Some smaller cities in the periphery are showing signs of recovery from industrial decline after the socialist era. For example, the city of Radom, with 215000 inhabitants in 2016 (Central Statistical Office, 2017), has experienced considerable industrial transition. While the traditional metalworking industry declined after 1989 , recently the city has attracted particularly specific technologies and further FDI. There are seven universities contributing to the local skill base (Pro Progressio, 2016; Radom City, 2018). Płock with 121300 inhabitants in 2016 (Central Statistical Office, 2017) is shaped by mineral oil and by petrochemical industries (particularly PKN Orlen S.A. and related companies). Płock has a university with general and technical disciplines (Plock, 2018). Pruszków with 60000 inhabitants in 2016 (Central Statistical Office, 2017) has automotive supply industries. The electro car "Sam" has been produced there since 2009 .

\section{Industry diversification and innovation capacity dimension}

Warsaw has a diversified industrial structure. It has a strong concentration of private services and public administration, which to a large extent reflects its position as the national capital and largest city in Poland as well as the location of regional headquarters of MNEs. It also has significant employment in manufacturing, including the highest concentration of electronics and high-tech manufacturing in Poland. There is substantial 
inward foreign direct investment (FDI) in industries producing consumer products for the domestic market (e.g. Coca Cola), and outsourced or offshored business services (e.g. Scandinavian Airlines). Most of these activities are characterised by low innovation capacity. The centre of Mazowieckie can therefore be described as diversified with low innovation capacity.

In contrast, the periphery is mostly rural, with some smaller urban centres. Its performance is much weaker than Warsaw on a range of economic indicators such as income per capita and education levels. Its industry diversification is dominated by agriculture, construction and some heavy industry. It has relatively low innovation capacity in these industries. Thus, the periphery can be characterised as specialised and with low innovation capacity.

\section{System differentiation dimension}

As set out in Annex B, the level of system differentiation in a regional innovation system can be described with reference to the quality and depth of its actors, networks and institutions. Once again, in Mazowieckie it is necessary to distinguish between the centre and the periphery of the region. The centre has high system differentiation with a large number and variety of actors and organisations, well-developed networks and social capital and adequate policy capacities. By contrast, the periphery has low system differentiation with few relevant actors and organisations and lack of networks and social capital.

\section{Implications of the pre-conditions for path development}

Table 3.1 provides a global characterisation of the industrial path transition pre-conditions in the centre and periphery of Mazowieckie showing the dual nature of the regional economy.

Table 3.1. Characterisation of Mazowieckie's regional pre-conditions for industrial path development

\begin{tabular}{llc}
\hline $\begin{array}{c}\text { Mazowieckie sub- } \\
\text { region }\end{array}$ & $\begin{array}{c}\text { Industry diversification } \\
\text { and innovation capacity } \\
\text { dimension }\end{array}$ & $\begin{array}{c}\text { System differentiation } \\
\text { dimension }\end{array}$ \\
\hline Mazowieckie centre & $\begin{array}{l}\text { Diversified industry; low } \\
\text { innovation capacity }\end{array}$ & High \\
$\begin{array}{l}\text { Mazowieckie } \\
\text { periphery }\end{array}$ & $\begin{array}{l}\text { Specialised industry; low } \\
\text { innovation capacity }\end{array}$ & Low \\
\hline
\end{tabular}

This dual structure suggests a need to develop separate strategies for the centre and the periphery with respect to the industry path development strategies to be promoted by smart specialisation policy.

The centre of the region (WMA) has strong potential for new path development. This reflects its capacity to promote related and unrelated diversification based on: 
1. Promoting collaborative innovation and skills development projects among businesses and research organisations in different specialisations.

2. Promoting business use of key enabling technologies (KETs) such as ICT, biotechnology, nanotechnology etc to transform their businesses.

3. Promoting exploitation of new knowledge in start-up and scale-up enterprises developed in its leading HEIs and research organisations.

In addition, it has the capacity for path importation by continuing to attract FDI.

One of the strands of a strategy for new path development in the centre should involve related diversification strategies based on innovation and skills development collaborations among actors from related activities. This is a relatively well-tested approach in regional development. However, at the same time, strategies to develop unrelated variety should be considered. These will require importing knowledge from new sources that are external to existing business activities. They are less secutre and longer term in nature than related variety strategies. Box 3.1 gives the example of how the region of Emilia Romagna has supported unrelated diversification and new path creation in this manner.

\title{
Box 3.1. A strategy for unrelated diversification and new path creation - Emilia Romagna, Italy
}

\begin{abstract}
Alongside path upgrading strategies and strategies of related diversification, more radical path development opportunities can be pursued by favouring unrelated knowledge combinations, underpinned by general purpose or key enabling technologies (KET), such as ICT, biotechnology, nanotechnology, etc. A number of regions are pursuing such strategies as part of their RIS3 strategies. Emilia-Romagna in Italy, Upper Austria and East Central Sweden are examples of regions that make use of KET in their RIS3 strategies to promote economic diversification and new path development.

As part of Emilia-Romagna's smart specialisation strategy, emphasis has been put on consolidating existing traditional, synthetic knowledge-based clusters (automotive, machines, ceramics, and food) by introducing key enabling technologies (KETs) such as nanotechnologies, advanced materials, microelectronics, photonics, industrial biotechnologies, advanced production systems and digital technologies in their knowledge bases and innovation processes. The strategy also emphasises fostering the emergence of new, highly innovative industrial systems, able to attract new qualified employment.
\end{abstract}

By contrast, the periphery of the region can more realistically expect to achieve path development through path upgrading of traditional sectors. It can also achieve further path importation from abroad with appropriate FDI policies. Although a common key strategy for regional industry path development is pursuing related knowledge combinations (regional branching), it does not appear a strong possibility for the periphery of Mazowieckie because of the low innovation capacity of existing industries in the region 
and the high specialisation of the periphery. An exception, however, is the possibility for related diversification in the periphery based on defence industries. This can be enabled by the traditional strong technological knowledge and skills base in the Polish defence sector, which has its own technical university, and the potential for spillover effects to other sectors. Indeed there appear to be instances of defence spillovers to aeronautics and space $\mathrm{R} \& \mathrm{D}$ activities in the region in the past.

Box 3.2 gives the example of the smart specialisation approach of the North Denmark region, which has also differentiated between path upgrading and path diversification and path creation strategies designed to meet the needs of both its central city and periphery. 


\section{Box 3.2. Smart specialisation in the North Denmark Region (NDR)}

The North Denmark Region shares some of the dual industrial structure features of Mazowieckie, although it is classified as an "innovation leader" in the EU's Regional Innovation Scoreboard and is thus more advanced in this respect.

The region displays a centre-periphery spatial structure, although the disparities between Aalborg and its periphery are not as great as between Warsaw and its periphery, given that Aalborg is only a second-tier city in Denmark.

As in Mazowieckie, the region also hosts both a set of traditional industries and a set of emerging research and knowledge-intensive industries. The traditional industries are in the food, construction, maritime and tourism sectors. They are dominated, as in Mazowieckie, by large, process-based firms and SMEs depending on an experience-based mode of innovation (see Annex A). The research and knowledge-intensive industries are based on commercialising research results from Aalborg University, as can be achieved from the Warsaw universities. Aalborg University is the only large university in the region and the third largest in Denmark, ranked among the 250-300 best in the world. The potential sectors for research commercialisations are in energy, health and life sciences, ICT and transport (including logistics and the maritime sector), where there are strong research milieus at Aalborg University.

North Denmark Region has developed a RIS3 strategy that aims at developing the existing as well as the future competitive strengths of the region, i.e. supporting both more traditional sectors and emerging sectors.

The Region has selected the following "growth areas" to be prioritised as the basis for a diversified specialisation of its smart specialisation strategy

National growth areas with considerable regional potential:

- Maritime industry - Logistics, green equipment and services.

- Energy and climate - Oil rigs, windmills, boilers, pumps and biogas plants.

- Information and Communication Technology - Potentials within ICT services, e.g. software and ICT consultancy.

- Health and welfare - Possibilities for developing local business access to develop and test innovative solutions in collaboration with the public sector.

- Foods - High quality non/semi-processed foods and agro technology.

- Tourism - Development of the regional tourism product towards high value niches. 
National growth areas with limited regional potential:

- Water, bio and environment - Possibilities for development in the recycling industry.

- Creative businesses and design - High specialisation in production of fur.

Regional strength:

- Construction and housing - Many specialised subcontractors for construction and Smart City development.

The sectors identified as representing national growth areas with considerable regional potential are given the greatest attention. They are supported as clusters in the RIS3 strategy. They include both traditional industries appropriate to development in the periphery and knowledgeintensive and research-based industries appropriate to the centre. Sectors with potentially less growth potential were also included in the strategy.

Source: Asheim et al., 2017a.

Overall, whereas path diversification and path creation appears realistic in the long-term in the centre of Mazowieckie, the industry path development in the periphery is more likely to occur through path upgrading. There is nevertheless also an opportunity to seek to combine the innovation potentials of the centre and the periphery in order to increase the path development opportunities of both centre and periphery as well as to help increase territorial cohesion within the region. The success of this strategy will depend on how far the continued use of an EDP in the smart specialisation strategy is able to mobilise innovative, Schumpeterian entrepreneurs from industry and start-ups, institutional entrepreneurs from universities and the public administration, and place leadership in both the centre and periphery of the region.

\subsection{Path development opportunities for Mazowieckie}

This section looks more closely at the potential for promoting new path development and economic diversification in Mazowieckie. It deals with the centre (WMA) and periphery separately in order to offer specific recommendations for the path development opportunities that are realistic options in different parts of the region.

\section{The periphery}

\section{The food sector}

The strongest asset of the periphery of Mazowieckie is its agricultural potential. Poland in general has a large and strongly export oriented agricultural sector. In this context, Mazowieckie has important potential as a food hub for Europe in the future. For the food sector to achieve a stronger international competitive position, a re-orientation is needed from the production of low value-added raw produce towards processed products with higher complexity and quality, aimed both at the final market and to move up the value 
chain in export. The potential of food processing is considerable, especially fruit (the region is already a large apple producer for export to EU markets), animal production (poultry and pork) and dairy products. Part of this modernisation should take place in close co-operation with HEIs, which can help businesses to apply knowledge to production (using an analytical knowledge base). ${ }^{15}$ For example, HEIs can facilitate the use of nanotechnology in food conservation and packaging, and biotechnology to produce functional food for customised diets, for instance directed to the growing market of obesity and other lifestyle diseases. In addition, many Western EU countries, especially neighbouring Germany, represent large markets for organic food, which Poland has excellent possibilities to supply, making use among other things of symbolic knowledge in marketing aimed at building Polish brands, possibly in co-operation with European retailers (McKinsey and Company, 2015).

The main strategy for the food sector can involve path upgrading through renewal and niche development in combination with path importation. However, there is also potential for "new path development" through unrelated knowledge combinations by making use of KETs such as biotechnology and nanotechnology in food products and production involving collaborations between HEIs and businesses. Further development of the cluster model to promote co-operation, knowledge sharing and more efficient supply chains would clearly facilitate this.

The UNIMOS AgroBioCluster is a good example of such co-operation. It is a European cross-sectoral organisation focusing on building trust-based partnerships between business, science, public administration and clusters to foster innovation and economic growth through cross-fertilisation between clusters from different sectors. These examples of new path development in the food sector would represent a concretisation of the "safe food" smart specialisation priority, which also illustrates the potential of combining economic areas (agriculture) with KETs (biotechnology and nanotechnology).

\section{Upgrading of traditional industries}

It is hard to see how other traditional industries in the periphery of Mazowieckie - e.g. construction, petrochemicals, energy, electronics, metal and machinery, and footwear could achieve a European competitive advantage, but it may be possible to upgrade them to become nationally competitive, and in some areas, to gain competitive advantage in within the Central and Eastern European area. The challenge is supporting SMEs in these industries to become more innovative, moving from a cost-based competition to a technological and quality-based competition, and moving up the value chain nationally and internationally where this is an option. Path importation might be an option in a few cases, as would closer collaboration with regional HEIs.

Generally, the key to making traditional industries more innovative and competitive is to strengthen the absorptive capacity of firms relying on an experience-based mode of innovation by increasing their R\&D competences. This is an important strategy for the upgrading of traditional industries, as research has demonstrated that combining experience and research-based modes of innovation makes firms perform better (Lorenz and Lundvall, 2006).

${ }^{15}$ Different knowledge types are discussed in Annex A. 
Another path to upgrading traditional industries is to support SMEs that continue to rely on an experience-based mode of innovation to move into high value-added niches by applying branding and design. This would support SMEs to climb the value-added ladder by introducing new products containing strong elements of branding and design to achieve product differentiation, leading to unique products and services at the high end of the global market.

However, low skills and a lack of $R \& D$ investment in traditional SMEs in the region are an important bottleneck to path upgrading associated with a low absorptive capacity for innovation. Together with problems of attracting and retaining highly qualified staff, this will have a negative impact on the potential of SMEs to become more innovative and to link up with R\&D organisations as well as with regional, national and international collaborators in global value chains and innovation and production networks. Addressing skills challenges in SMEs must be a a key priority for the smart specialisation strategy in the periphery.

\section{The centre}

\section{Knowledge-intensive business services}

Warsaw has strong locational advantages for business services. However, so far the majority of business service activities have been either national or regional headquarters of domestic firms and FDI or outsourced BPO and SSC activities that are relatively low in knowledge and skill intensity. There is potential to attract and develop more knowledgeintensive business services based on the advantages of lower cost skills and talent and proximity to several high-quality research universities. Given the quality of the capital's research in ICT, physics and medicine, examples of knowledge-intensive business services to differentiate into in the future would be big data analytics, data storage and remote health diagnostics (McKinsey and Company, 2015). Path importation in the form of higher quality FDI can also play an important role in this. In addition, start-ups and scale-ups in business services can be developed based on knowledge coming out of basic and applied research at the four large universities in Warsaw.

\section{High-technology manufacturing}

There is strong potential for new path development in the centre of Mazowieckie through unrelated diversification and new path creation in the energy, medicine and pharmaceutical industries. This will involve start-ups and scale-ups, transformation of existing businesses and strategic FDI attraction making use of the key strengths of Warsaw's HEIs in the biotechnology, ICT, nanotechnology, electronics and photonics KETs. In addition, there is potential for related diversification development in transport technology based on the very competent research milieu in aeronautics and space technology at the Warsaw University of Technology, which works together with leading international companies such as Airbus and Boeing.

With respect to pharmaceuticals, it has been suggested that Poland could become a pharmaceutical hub for Europe by developing capabilities as a manufacturing centre for complex generics and biosimilar products (McKinsey and Company, 2015). Warsaw is particularly well placed in this respect given its research capabilities, but FDI attraction will be important to put in place a knowledge exploitation/production capacity in the short term. 
An example of the potential of KETs is provided by a photonics firm named "InPhoTech", which was founded in 2010 by a group of engineers and researchers with experience in cooperation with big industry. Photonic solutions can be applied to virtually all industries and are having an increasing influence on all aspects of human life. Optical fibres and their components open great opportunities for other areas of the economy, such as medicine, transportation, energy, construction, mining, defence and space (unrelated knowledge combinations). The firm is responsible for $R \& D$ and fabrication of speciality optic fibres, innovative optical fibre components and devices in many large European projects, cooperating among others with Airbus Defence and Space, European Space Agency, and leading European technical universities (e.g. École polytechnique fédérale de Lausanne) and research institutes (e.g. Leibniz Institute for Innovative Microelectronics).

This is a good example of a high-tech start-up that has benefitted from access to highly skilled people and proximity to leading research universities combined with high international cost competitiveness in Warsaw. Today the company has 50 employees and a modern research and technology facility near Warsaw. Thus, the firm is primarily involved in R\&D activities, which produce vital knowledge that can lead to new path development. However, in order to achieve this, the firm needs to scale up and develop an applied engineering exploitation and production capacity. This will be very demanding of capital, and probably beyond the reach of this firm. This bottleneck could be addressed by public initiatives to strengthen venture capital availability.

Although the production of intangible IT products, such as internet apps and software, is much less demanding of financial capital, and can be more easily handled by start-ups from HEIs in incubators and science parks, it is also important to host production capacity locally to secure knowledge and continued innovation from the application of the technology. Inspiration in this respect could be taken from the innovation strategy of the Upper Austria region, which applies a strategy of an "innovation chain" of research - education application. This involves a strong focus not only on knowledge exploration (mostly through applied research in co-operation with industry) but also on knowledge exploitation (application) as well as on competence building (skills development and consultancy and mentoring for management) to strengthen the absorptive capacity of SMEs in the region.

An R\&D-based strategy is, in general, a very costly path development strategy, with a high failure rate and strong results in new firm growth and job generation emerging only in the long-term. Attempts to develop and exploit Warsaw's strong research base in KETs for industry development should therefore focus on areas where Warsaw hosts leading technological research where there is also strong commercialisation potential. This is likely to be in the areas of energy, medicine and pharmaceutical industries. At the same time, there is particular value in investing in $R \& D$ involving a combination of analytical/scientific and synthetic/engineering R\&D-based knowledge. This is often present in the region due to a strong technological competence base and tradition, and is associated with a strong exploitation or commercialisation potential. It is R\&D and commercialisation opportunities in these areas that should be favoured for new path development in Warsaw, rather than more costly and less probable opportunities in "pure" analytical knowledge such as biotechnology.

Warsaw's smart specialisation policy can stimulate this development by favouring R\&D and innovation projects in energy, medicine and pharmaceutical industries. One of its tools is to start to use public procurement for innovation to facilitate the development and production of products based on the core research and technological competences of the region. Together with more national funding for targeted, strategic research, and the 
mobilisation of accessible EU funding through Horizon 2020 and other relevant programmes in a smart way, a considerable amount of funding should be available for the commercialisation of these technologies. In addition to creating this critical mass of R\&D in the targeted areas, the regional smart specialisation policy can support its exploitation by favouring start-ups and scale-ups, including university spin-outs, and knowledge exchange between HEIs and businesses in these fields.

This strategy should help to generate start-ups and scale-ups, high-qualified jobs, and the attraction of FDI. In many ways, the opportunities given by access to leading research milieus and a highly qualified labour force in Warsaw's HEIs are being exploited in only a very limited manner.

\subsection{Importance of multi-stakeholder co-operation}

There are promising prospects for Mazowieckie to achieve new path development, especially in the centre of the region, based in particular on the key research strengths of Warsaw's leading HEIs. This can be achieved through unrelated path diversification, new path creation, and path importation to provide exploitation and production capacity.

Success in these efforts will require multi-actor co-operation. In particular, it is critical to build up close university-industry co-operation, a well-developed network of clusters in each targeted industry, and an adapted organisational and institutional support structure for smart specialisation.

One of the key tools available to build multi-stakeholder co-operation is the strengthening of cluster organisations and the promotion of cross-cluster co-operation. Relationships among actors within clusters and across clusters is a critical vehicle for knowledge sharing, innovation co-operation and skills development co-operation and developing more efficient supply chains nationally and internationally.

Mazowieckie already has a number of cluster organisations but they are weakly resourced and do not match closely with the future industry opportunities that have been identified in this report for the region. These organisations need to be strengthened in the key future industry development areas and mechanisms introduced to strengthen cross-cluster cooperation. It is also important that actors in the periphery of the region are included in these cluster co-operations.

Mazowieckie may take some inspiration from the cluster development model of the region of Upper Austria, which is described in Box 3.4. 


\section{Box 3.3. Cluster co-operation in Upper Austria}

Co-operation across clusters in the region of Upper Austria is promoted by bringing all the clusters in the region under one organisational umbrella called "Clusterland" with its own director and advisory board working under the auspices of the Upper Austrian Business Agency. Clusterland co-ordinates the various clusters in the region to facilitate co-operation in the crossroads of clusters. The aim is to support cluster actors to break out of the value chain of their own cluster by looking outside of their cluster box and to foster crossfertilisation among clusters to strengthen their innovative capacity and competitive advantage.

The region also promotes international cross-cluster co-operation. An example is the Interreg project "Alpine Space S3-4AlpClusters", which focuses on the implementation of smart specialisation in clusters. The project uses smart specialisation policy to foster innovation processes and spark entrepreneurship within clusters and seeks to implement smart specialisation through clusters. The initiative launches cross-regional, co-ordinated actions between the different clusters and regions involved in the Alpine Space and enhances transnational cluster co-operation. The final aim is to generate critical mass for SMEs and to improve the framework conditions for innovation in the Alpine Space.

Further information: http://www.alpine-space.eu/projects/s34alpclusters/en/home

A second key tool for developing multi-actor co-operation and integrating the centre and the periphery of the region in smart specialisation development is the entrepreneurial discovery process (EDP). The EDP approach is a bottom-up strategy relying on mobilising people in a region with an entrepreneurial mindset from all sectors of the community or society and involves building broad local and regional development coalitions. It is important to reinforce EDP actions in Mazowieckie with this end, in terms of engaging the key policy, research and business stakeholders in promising specialisations in the identification and delivery of common innovation, entrepreneurship and skills development initiatives.

\subsection{Conclusions and policy recommendations}

This section highlights the potential for significant positive structural change in the Mazowieckie regional economy leading to productivity growth. There are two main channels. The first channel involves exploiting research in KETs in Warsaw HEIs and elsewhere and integrating this into the business models of existing businesses and into new start-ups and scale-ups in specific areas of knowledge-intensive business services and hightechnology manufacturing. This is a strategy that is particularly appropriate to conditions in the centre of the region. The second channel involves upgrading traditional sectors in the periphery of the region by raising skills and innovation capacities in SMEs and building 
social capital and trust. This can particularly focus on upgrading the quality of products through food processing, branding and organic food.

As well as targeting research and innovation investments towards these specialisations, promoting entrepreneurship in them, and building SME skills and management capabilities, there are two key policy tools for promoting industry transition that need to be strengthened further, namely cluster organisations and networks and the use of the EDP in smart specialisation policy. 


\section{Box 3.4. Recommendations on smart specialisation and industry path development}

Adapting industry path development strategies to regional pre-conditions

1. Increase policy emphasis on new path development aimed at diversifying the economy into more technologically advanced activities with greater knowledge complexity.

2. Increase prioritisation in the smart specialisation strategy to emphasise a small number of more specific specialisations.

3. Adopt a policy approach that is designed to meet the distinct needs of both the centre and the periphery of the region.

4. Strengthen the entrepreneurial discovery process by actively engaging with multiple stakeholders to identify and mobilise actions behind the main opportunities.

\section{Path diversification and path creation in the centre}

5. Develop an R\&D based strategy to capitalise on the Warsaw's strong research base in biotechnology, ICT, nanotechnology, electronics and photonics to promote diversification and new industry creation in business services (e.g. for big data analytics, data storage, remote health diagnostics), and in high technology manufacturing (e.g. in energy, medicine and pharmaceuticals).

6. Accelerate the commercialisation of new research results through stimulating close co-operation between HEIs and industry as well as competence building to strengthen the absorptive capacity of SMEs.

7. Use public procurement for innovation to facilitate the development and production of products based on the core research and technological competences of the region.

8. Support an upgrade in the business services sector by moving from labour cost competition to a model based on competing on innovation strengths, including leveraging the proximity to several high-quality research universities.

9. Promote related diversification in transport technology by capitalising on the competent research milieu in aeronautics and space technology at the Warsaw University of Technology.

10. Pursue path importation through FDI to support diversification in the short term, including through developing production capacities in areas of research specialisation.

\section{Path upgrading in the periphery}

11. Upgrade food production from low value-added raw produce towards processed products with higher complexity and quality in the final market while also moving up the value chain in export.

12. Support new industry creation by employing KETs such as biotechnology and nanotechnology in food production, (e.g. for food conservation, packaging, functional food, and organic food). 


\section{References}

Asheim, B.T., (2007), "Differentiated knowledge bases and varieties of regional innovation systems", Innovation: The European Journal of Social Science Research, Vol. 20/3, pp. 223-241, http://dx.doi.org/10.1080/13511610701722846.

Asheim, B., M. Grillitsch and M. Trippl (2017a), "Introduction: Combinatorial Knowledge Bases, Regional Innovation, and Development Dynamics”, Economic Geography, Vol. 93/5, pp. 429-435, http://dx.doi.org/10.1080/00130095.2017.1380775.

A.T. Kearney (2017), Global Cities 2017: Leaders in a World of Disruptive Innovation, https://www.atkearney.com/documents/10192/12610750/Global+Cities+2017++ Leaders+in+a+World+of+Disruptive+Innovation.pdf/c00b71dd-18ab-4d6b-8ae6-526e380d6cc4.

Central Statistical Office (2017), Population. Size and Structure and Vital Statistics in Poland. Warsaw 2017, http://stat.gov.pl/en/

Dominiak, J. (2011), "Level of development of electronic services in Poland compared with the European Union states", Questiones Geographicae, Vol. 30/2, pp. 57-70 http://dx.doi.org/10.2478/v10117-011-0018-9.

Jones Lang LaSalle (2017), Warsaw Office Market 2016, http://absl.pl/wpcontent/uploads/2016/02/Warsaw-Office-Market-2016.pdf.

Kasprzak, R. (2015), "Creative industries in the Polish economy”, Quaestiones Geographicae, Vol. 34/2, pp. 35-43, http://dx.doi.org/10.1515/quageo-2015-0013.

Lorenz, E. and B. Lundvall (2006), How Europe's Economies Learn : Coordinating Competing Models, Oxford University Press, Oxford.

McKinsey and Company (2015), "Poland 2025: Europe's new growth engine”, http://www.mckinsey.pl.

Płock (2018), Płock, http://www.plock.eu/de/um_die_stadt_herum.html.

Pro Progressio (2016), "Focus on Radom Investment Attractiveness", http://en.investinradom.pl/data/dataPublicator/focus-on-radom-en-august-2016_3.pdf.

Wójcik, M. and A. Traczyk (2017), "Changes in the Spatial Organisation of Fruit Growing at the Beginning of the 21St Century: The Case of Grójec Poviat (Mazovia Voivodeship, Poland)", Quaestiones Geographicae, Vol.36/2, pp. 71-84, https://content.sciendo.com/view/journals/quageo/36/2/articlep71.xml 


\section{Knowledge exchange and skills}

This section assesses the enablers and bottlenecks to entrepreneurship and emerging industries in Mazowieckie in the areas of knowledge exchange and skills developments. It offers policy recommendations and inspiring policy practices from other countries.

\subsection{Knowledge exchange}

Knowledge exchange is a critical process in regional industrial path development. It can support radical innovation across a broad spectrum of sectors in urban innovation hubs such as the centre of Mazowieckie (Wetzstein and Le Heron, 2010). It can also support incremental and applied innovation in niches of traditional industries in suburban spaces, smaller cities and rural-peripheral areas (Foray, 2016; McCann and Ortega-Argilés, 2017; McCann, van Oort and Goddard, 2017), as found in the periphery of Mazowieckie. In both types of area, it is important for knowledge to flow across different economic sectors and across firms that differ with regard to foreign/domestic ownership or technology and knowledge, with different actors combining competencies by engaging in interactive learning (Dettmann et al., 2016 $[5]$ ).

Mazowieckie possesses an important knowledge exchange enabler in the form of local infrastructures that facilitate proximity across innovative firms in related areas. They include technology transfer centres, business incubators, fablabs, co-working spaces and creativity centres. Both the public and private sectors have been successful in investing in these types of facilities in the region.

However, spatial proximity between firms will not necessarily generate knowledge exchange. Here, there is an important bottleneck in Mazowieckie, in the form of lack mutual trust among local actors. Mutual trust is a critical factor in promoting interaction and the exchange of knowledge and innovative ideas ( $\mathrm{Li}, 2005)$. Knowledge exchange requires an open atmosphere and exchanges among self-organising teams and innovative milieu (Leydesdorff, 2006; Moulaert and Nussbaumer, 2005).

The lack of mutual trust and an open innovative milieu in Mazowieckie is something shared with many other regions in Central and Eastern Europe (Marinelli, Edwards and Mironov, 2017). The lack of trust is evident, for example, in a low willingness of HEIs to collaborate with companies and vice versa, as discussed in OECD/EU (2017). There is also a limited readiness among companies to participate in collaborative public policy initiatives in the region, as opposed to accessing grants and subsidies for projects in their own particular firm.

Policy cannot create mutual trust and an open innovative milieu from scratch (FromholdEisebith and Eisebith, 2005). However, it can gradually build it by creating opportunities for communication between actors on a level playing field and facilitating repeated meetings among various actors. This can lead to cohesion, a coherent spirit and solidarity 
among the actors over the course of time, facilitating knowledge exchange even in contested areas (McCann and Ortega-Argilés, 2017; O'Connor et al., 2018). Conditions appear to be propitious in Mazowieckie for building mutual trust and collaboration, reflecting a strong awareness among local actors of the importance of trust and collaboration for innovation and an awareness of a need for change in the regional culture in this area.

Policy has helped build mutual trust and collaboration in the innovation system of the Stuttgart region in Germany over the years, and this offers a potential model for policy development in this area in Mazowieckie (Box 4.1).

\section{Box 4.1. Policy to build mutual trust and collaboration, Stuttgart, Germany}

Fuchs and Kempermann (2012) show how a positive industry response to the 2008-2009 global financial crisis was facilitated by mutual trust and co-operation among industry stakeholders in the region of Esslingen, Göppingen and Rems-Murr-Kreis in Stuttgart, BadenWürttemberg.

This mutual trust and collaboration had been long-standing in the region. In particular, the local government authorities went about creating the basis for mutual trust and collaboration as of the 1980s (Herrigel, 2000). They achieved this by organising a range of regional conferences, meetings, workshops etc. Local government secured the involvement of a diverse range of actors in the meetings in order to avoid an overdomination by the automotive supply industry, the largest exporting sector in the region. The meetings brought together different actors on a regular basis and helped to identify win-win constellations. This included contacts between employers and employees' representatives with a view to retaining labour during the crisis and retraining and redeploying labour where necessary, including the exchange of skilled staff locally and closer interaction between vocational education and training colleges and companies.

\subsection{Skills}

\section{Labour market conditions}

In Warsaw, the rate of registered unemployment has been consistently on the decline in recent years and has remained low, usually far below 6\% (Statistics of Warsaw, 2018). Monthly wages are above the national average (Statistics of Warsaw, 2018). Labour costs in Warsaw are nevertheless lower than in Western European cities, making Warsaw attractive for inward FDI.

The labour market in the periphery is much less healthy in terms of unemployment and wages. Table 4.1 illustrates the strong differences between the Mazowieckie region as a whole and the central city of Warsaw in terms of basic labour market conditions. 
Table 4.1. Characteristics of the labour market in 2017

\begin{tabular}{lccc}
\hline & Poland & Mazowieckie & Warsaw \\
\hline Population (millions) & 38411 & 5384 & 1764 \\
Unemployment rate (\%) & 5.9 & 5.1 & 1.8 \\
Average gross wages and salaries in enterprise sector (PLN) & 4825 & 5744 & 6093 \\
\hline
\end{tabular}

Source: https://stat.gov.pl/en/basic-data/, accessed on 23 August 2018

\section{Training supply}

Warsaw is well-established with regard to tertiary education. More than three quarters of the region's HEI students are in Warsaw, which has approximately 240000 higher education students and 60000 graduates (Central Statistical Office, 2017). On the other hand, higher education levels are weaker in the rural areas of the region, despite several HEIs located there (Kaminska, 2013).

Vocational education and training (VET) is strong in the region, and there has been substantial VET investment both in the centre and the periphery (Kowalik and Zawada, 2017). Overall, there are 620 VET colleges in Mazowieckie. Focusing on technical VET colleges, there are 97 in Warsaw, 45 in the Radom Poviat, 35 in Siedlce Poviat, 34 in Ostroleka Poviat, 19 in Ciechanow Poviat and 19 in Płock Poviat. There are also four "centres of vocational and lifelong learning" in Warsaw, Ostroleka, Radom and Siedlce, and seven medical post-secondary schools in Minsk Mazowiecki, Ciechanow, Otwock, Płock and Przasnysz and Warsaw (a medical and a socio-medical post-secondary school). Moreover, the regional government runs post-secondary schools throughout the region. Examples of important VET investments in the region include regional government support for the "regional dormitory" in Ostroleka, the "school complex no. 3", a technical school in Wyszkow, and an upper-secondary school complex in Garbatka-Letnisko.

\section{Skills levels}

The availability of appropriate workforce skills is a key enabler for innovative start-ups, scale-ups and SME innovation and for industry path development in a region. However, skill shortages are often a substantial challenge, both in tight urban labour markets in metropolitan hubs and in rural areas with a lack of capable workforce for specialised fields of production (Boschma, Iammarino and Steinmueller, 2013).

In line with the strong training supply cited above, Mazowieckie has a high share of workers with high skills, as shown in Figure 4.1. This is an enabler for innovative entrepreneurship and emerging industries. 
Figure 4.1. Education of employed persons in Mazowieckie $\left(1^{\text {st }}\right.$ quarter 2018)

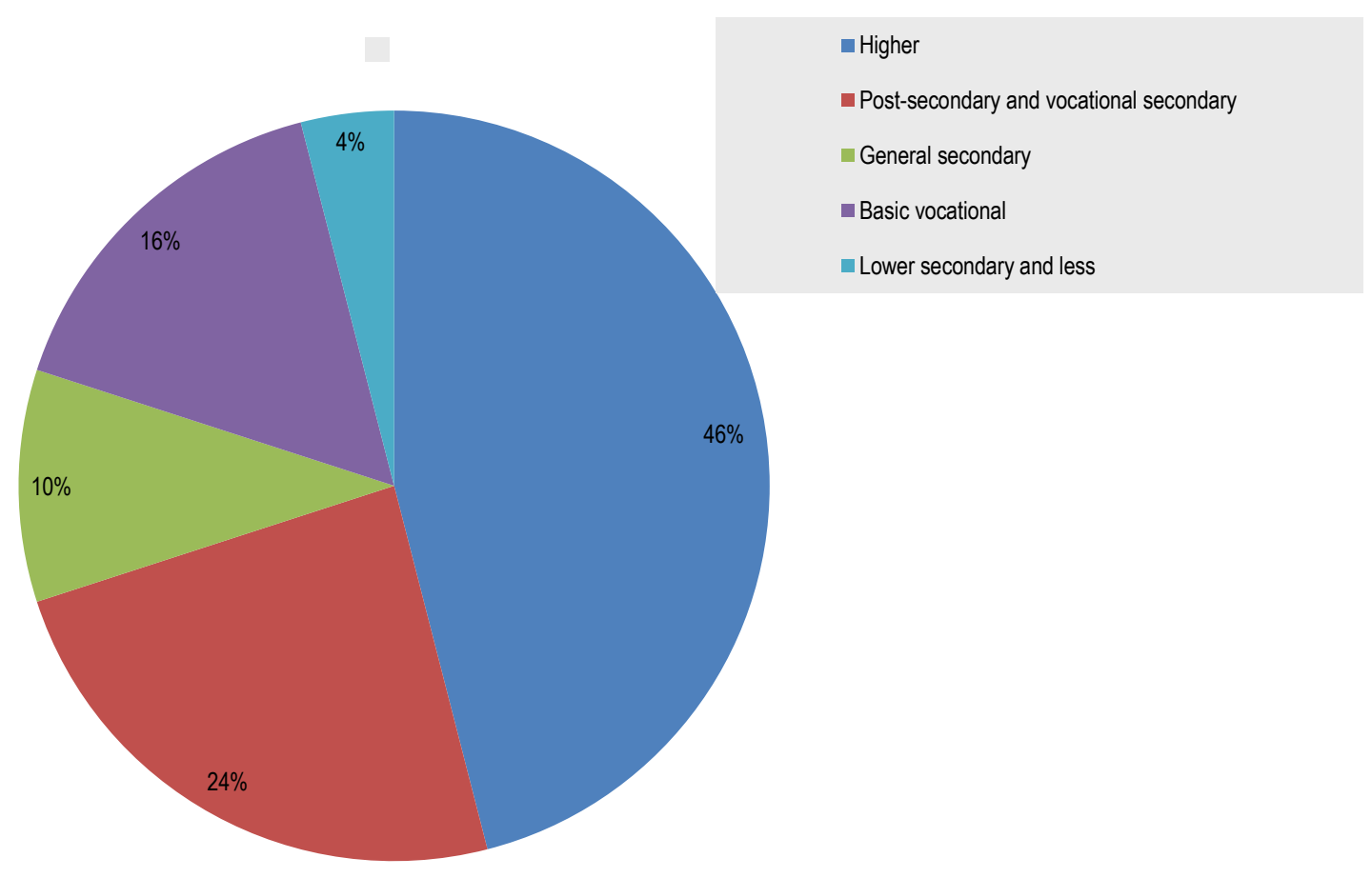

Source: http://warszawa.stat.gov.pl/en/communiqus-and-announcements/brief-information/other/economicactivity-of-population-in-mazowieckie-voivodship-in-i-quarter-2018,1,15.html, accessed on 24 August 2018

Moreover, Mazowieckie had demonstrated good educational attainment results on the OECD Programme for International Student Assessment (PISA) 2015, and the Trends in International Mathematics and Science Study (TIMMS) 2015, and Progress in International Reading Literacy Study (PIRLS) 2016.

Inward migration is a potential source for strengthening regional skills further. Interregional migration within Poland generates a high net population inflow to Warsaw and even more to the neighbouring areas (urban sprawl). The districts in and around Warsaw receive immigration not only from the rest of Mazowieckie, but also from other Polish regions (Statistics of Warsaw, 2018). There is also positive net inward international immigration, particularly in Warsaw and particularly from neighbouring countries such as Ukraine, Belarus and the Russian Federation. However, many immigrants have a rather low level of education and training and tend to work in low-skilled segments of the labour force, including in the shadow economy (Nikulin and Sobioechowska-Ziegert, 2017). There are relatively few highly skilled immigrants (Di Berardino, D'Ingiullo and Onesti, 2017). In other regions, highly-skilled international migrants have played key roles in entrepreneurship and emerging industries. They have been referred to as the "new argonauts" in the USA (Saxenian, 2012, p. 28). There is also a potential pool of skilled international migrants in the form of returnee migrants to Poland; e.g. Polish people who have worked and picked up skills and networks in the USA. However, there have sometimes been problems in securing their effective reinsertion into the Polish economy and many have left Poland. 
To further broaden the pool of skilled labour, women can be further supported to participate in the labour market. While in Warsaw over $90 \%$ of children attend kindergartens, in rural communities in the region this figure is only about $50 \%$.

\section{Skills policies}

The regional government is aware of the need to improve the skill formation system to meet the current and future requirements of entrepreneurs and businesses. The priorities include further support for digital skills, problem-solving capabilities, social competences and entrepreneurship competences. This requires a rethinking of the approach to education and training in the region. Whereas entrepreneurs and businesses have traditionally played only a weak role in Poland in shaping and participating in training and curriculum development (Reum, 2016), increasing their involvement is an important requirement for ensuring that education and training meet the needs of enterprises and entrepreneurs. This applies both to making inputs to the identification of skill needs and the design of training and courses and to participating in the teaching itself.

One of the principal avenues pursued by the regional government for increasing the relevance of training to businesses and increasing business inputs into the design and delivery of training has been the exploration of dual VET practices. Introducing dual training approaches imply that teachers increasingly become mentors and coaches, and that learners develop social competencies including collaboration and teamwork, and selfcompetencies such as responsibility for the product and the production process (or for the service). In addition, dual training approaches increase the support that businesses provide to VET colleges for training of the students they work with. For example, local businesses getting involved in dual training approaches in Mazowieckie have been providing VET colleges with up-to-date digital technologies for training. Box 4.2 discusses the crossboundary transfer of VET practices. 


\section{Box 4.2. Dual VET approaches in Germany}

Germany, Austria and Switzerland have "corporatist" skill formation systems to train people after leaving general schools, characterised by close interaction among various stakeholders (Busemeyer and Trampusch, 2012). They are "dual" systems because the apprentices attend both VET colleges and companies. Recently several countries within and beyond Europe have become interested in adopting practices of these systems as a means to overcome skill shortages and reduce youth unemployment (Fuchs, Schamp and Wiemann, 2016).

Clearly it is impossible (and not desirable) to transfer a complex skill formation system from one country to another. For example, in Germany, a number of broader framework conditions support successful dual training:

- The state finances VET colleges and thus bears part of the costs of the dual training.

- There is a legal basis for dual VET in the form of Vocational Education Legislation, with the federal state ministers of education specifying framework curricula (Pilz, 2009).

- Firms, employers' federations, industry chambers, trade unions, the German state and the federal state authorities provide for up-to-date and practice-oriented content.

- The dual training leavers' certificate is state-approved, while compulsory membership chambers of commerce perform the final certification (Pilz, 2009; Pilz, 2017).

However, there are several cases in which relevant VET practices have been selectively implemented in countries with less applied skill formation systems (Wiemann and Fuchs, 2018; Wiemann et al., 2018), focusing particular on adopting the core of the German dual VET model, namely practice-oriented training in companies and apprentices' handling of modern technologies (Barabasch and Wolf, 2009).

Local embeddedness is crucial, e.g. interaction among MNE subsidiaries, local schools and universities, chambers of foreign trade, and others, and a spirit of mutual commitment among employers and employees, teachers and learners (Wiemann and Fuchs, 2018, Wiemann et al., 2018).

There are strong opportunities to develop dual VET approaches in Mazowieckie, reflecting strong regional government influence on VET colleges in Poland (Reum, 2016), which can encourage VET college to respond to various technological, organisational and other changes (Wiemann and Fuchs, 2018; Wiemann et al., 2018).

A number of activities have already been introduced in Mazowieckie moving towards the more widespread practice of dual training, such as public support for dual training scholarships, engaging large FDI companies in dual training initiatives, and encouraging local employers to create more attractive work conditions at the intermediary skill level (OECD, 2016). This is a good basis to encourage further engagement of businesses in VET in the region. 


\section{Skills retention and transfer}

An issue that has proved important in maintaining high skill levels in SME workforces in countries such as Germany has been a flexibility to retain the pool of skilled workers at times of crisis. For this, the labour market system needs mechanisms to enable firms faced with a downturn to retain skilled staff until conditions improve, and mechanisms to transfer skilled labour to other firms if companies go bankrupt or have to shed skilled staff.

Reduced working hours arrangements have proved to be an effective mechanism to retain skilled staff. During the 2008/09 crisis, German firms, for example, used reduced working hours, as allowed by German law, to retain their skilled labour until conditions improved. Reduced working hours arrangements have to be announced at the employment agency, and the work councils have to agree. If accepted, reduced working hours are supported by public funds. Reduced working hours is an instrument for companies to keep their experienced, skilled core staff during the crisis, and at the same time, it ensures the jobs of the workers and offers incomes during the period of reduced working hours. Such a mechanism helps companies to keep highly qualified staff and prevent unintended turnover.

Polish law allows firms to reduce working time for operational or seasonal reasons. Announcing reduced working hours can therefore potentially be an important tool to maintain skills in Mazowieckie if well understood by companies and employee representatives. In Germany, management and workers' representatives may negotiate social plans as the basis for short-term working. However, a common barrier is that when companies arrive at and recognise crisis situations, management and employees' representatives are often unprepared and, thus, look for ad hoc solutions (Filipiak and Mühge, 2018). A more formal structure could play an important role in Mazowieckie in enabling employers and employees to find support in negotiating reduced working hours agreements, or in supporting the transfer of skilled workers from downsizing firms to other firms in the regional economy requiring these skills. In Sweden, Job Security Councils are permanent bodies that fill this function and could provide policy development inspiration for Mazowieckie (Box 4.3). 


\section{Box 4.3. Job Security Councils, Sweden}

Job Security Councils support the transfer of skilled employees from one job to another. They were created in Sweden to support highlyqualified personnel during the economic crisis of the 1970s. The Councils were successful and have since been retained and expanded in the Swedish system.

Jos Security Councils are organised as foundations, regulated by sectoral collective agreements and financed by companies. They are controlled by employers' and employees' representatives.

There were 15 Job Security Councils in Sweden in 2018. They are specialised in various economic sectors and offer particularly tailored suggestions to workers who need to change their jobs. Usually $85 \%$ of employees who lose a job find a new job within the same year in Sweden, which is mainly the result of the activities of the Councils.

An example is the Kommunala Företagens Samorganisation (KFS) in Stockholm. It has 500 member companies in the municipality with 30000 employees. The companies come from many different sectors, such as energy, health, transport etc.

Another example is Trygghetsrådet (TRR), a larger organisation of 32000 mostly private companies and 850000 employees, with the engagement of unions as well.

The regular contacts between these organisations and their employer members facilitate the identification of cases where skilled workers need a new job placement and help to broker the agreements. The Councils also help skilled workers to find new solutions in cases of mass redundancy, e.g. where a company goes bankrupt.

In Mazowieckie, a regional Job Security Council could be created or a Job Security Council for one or more of the regional smart specialisations in order to help institute reduced working hours agreements or transfer of skilled staff to new companies.

Source: Filipiak and Mühge, 2018.

\subsection{Conclusions and policy recommendations}

This section has highlighted two major areas for strengthening knowledge exchange and skills development for the promotion of entrepreneurship and emerging industries in Mazowieckie. First, a major challenge to facilitate knowledge exchange is to build mutual trust that will facilitate positive interactions among businesses, HEIs and other actors in innovation. Second, VET will play a critical role in helping to address spatial disparities within the region, prevent skill shortages and improve the pool of skilled labour. 
There are several windows of opportunity for the region in facing this agenda. Opportunities for industry path development have been identified in the previous section including in the areas of knowledge-intensive business services (including finance and ICT) and high-technology manufacturing in the centre, and in various traditional industries (including the food, automotive and chemicals industries) in the periphery. Increasing knowledge exchange collaborations among actors in these industries and across them will be critical, and can be promoted with a range of measures to facilitate collaboration and help build trust among actors. In addition, the region can profit from the fact that there is strong decentralisation of the national VET system to regional level in Poland, which can enable further experimentation with dual training and job security initiatives for skilled workers. These areas of development should be priorities in any reconsideration of Mazowickie's smart specialisation policies in 2019-20 and in the new EU Financial Perspective from 2021 to 2027.

In particular, to cope with regional disparities, it is important to create positive prospects for young people to start their family in the periphery of the region, instead of migrating to the capital. Smaller cities and rural areas in the periphery can be supported by further increasing knowledge exchange in the smart specialisations, including knowledge exchange links with actors in the hub in the centre and with actors outside of the region. In particular, it is important to increase access to KETs for traditional SMEs in traditional sectors and facilitate their integration into SME business models.

With regard to education and training, the region has a comprehensive setting of HEIs, VET colleges and schools. However, the region should further build skills for applied knowledge and practically oriented competences, through VET in particular. Dual training initiatives will be an important part of the solution. This requires both FDI and indigenous firms to engage with the VET system and contribute to the generation of applied up-to-date skills, modern machinery in training centres, and teaching and training. The emphasis should be not just on technical skills, but also on transversal competences, including digital, social and entrepreneurship skills and developing self-competences of learners.

To retain skills, the regional economy and individual firms also need mechanisms to recover efficiently from economic downswings. If a company cannot recover from a crisis, mechanisms such as social plans or Job Security Councils can serve as useful tools to retain or redeploy skilled labour, potentially with public financial contributions.

Local actors need to consider together the elements of policy that are needed to improve the local skill pool and knowledge exchange in the region, as an extension of the region's existing smart specialisation strategy EDP. Inspiration can be taken from policy approaches in other countries, such as dual training in Germany and Job Security Councils in Sweden. Obviously there cannot be a simple transfer of models or mechanisms from one country to another. Rather, what is needed is an adaptation of policy ideas to the conditions of Mazowieckie, based on the collective knowledge and ideas of regional policy stakeholders. 


\section{Box 4.4. Recommendations on knowledge exchange and skills}

Knowledge exchange

1. Increase incentives for HEI engagement with industry at the level of the HEI, department and individual researcher.

2. Provide a range of forums and initiatives to foster multi-actor collaboration and help build mutual trust for knowledge exchange, including by organising regional conferences, meetings, and workshops involving diverse actors to identify win-win projects and initiatives.

\section{Labour market}

3. Promote greater integration of highly skilled international (re)migrants and women into the labour force to help address future skill shortages.

4. Encourage stronger collaboration between the higher education and vocational education and training systems and businesses, supporting foreign direct investors, large domestic firms and SMEs in making inputs to the identification of skill needs, the design of training and courses and participating in teaching.

5. Include skills issues in the discussions of the smart specialisation working groups to build a shared narrative on future skills and training needs and potential collaborations.

6. Support the development of job security councils to assist with negotiating reduced working hours arrangements and transferring skilled labour from firms affected by crises and redundancies. 


\section{References}

Boschma, R., S. Iammarino and E. Steinmueller (2013), "Editorial: Geography, Skills and Technological Change", Regional Studies, Vol. 47/10, pp. 1615-1617, http://dx.doi.org/10.1080/00343404.2013.823306.

Busemeyer, M. and C. Trampusch (2012), "The Comparative Political Economy of Collective Skill Formation", in Busemeyer, M. and C. Trampusch (eds.), The Political Economy of Collective Skill Formation, Oxford University Press, Oxford.

Central Statistical Office (2017), Population. Size and Structure and Vital Statistics in Poland. Warsaw 2017, http://stat.gov.pl/en/.

Dettmann, E. et al. (2016), “The Importance of Localized Related Variety for International Diversification of Corporate Technology", Regional Studies, Vol. 50/10, pp. 1648-1662, http://dx.doi.org/10.1080/00343404.2015.1049994.

Di Berardino, C., D. D’Ingiullo and G. Onesti (2017), “International Skilled-Migration and Regional Growth in Poland”, Journal of Applied Economic Sciences, Vol. 3/49, pp. 863-874.

Filipiak, K. and G. Mühge (2018), "Job Security Councils - Impulse für die Mitbestimmung”, Analyse im Auftrag der Hans-Böckler-Stiftung, 11, http://www.boeckler.de/.

Foray, D. (2016), "On the policy space of smart specialization strategies", European Planning Studies, Vol. 24/8, pp. 1428-1437, http://dx.doi.org/10.1080/09654313.2016.1176126.

Fromhold-Eisebith, M. and G. Eisebith (2005), "How to institutionalize innovative clusters? Comparing explicit top-down and implicit bottom-up approaches", Research Policy, Vol. 34/8, pp. 1250-1268, http://dx.doi.org/10.1016/J.RESPOL.2005.02.008.

Fuchs, M. and H. Kempermann (2012), "Flexible specialization: Thirty years after the 'second industrial divide': Lessons from the German mechanical engineering industry in the crisis 2008 to 2010", in M. Fromhold-Eisebith and M. Fuchs (eds.), Industrial Transition: New Global-Local Patterns of Production, Work, and Innovation, Ashgate, Burlington and Farnham.

Fuchs, M., E. Schamp and J. Wiemann (2016), "Vocational education and training goes global?The role of global-local skill development strategies in the internationalisation of knowledge on the shop floor of multinational companies", Geographische Zeitschrift, Vol. 104/3, pp. 140-157.

Herrigel, G. (2000), "Large Firms and Industrial Districts in Europe: De-Regionalization, ReRegionalization and the Transformation of Manufacturing Flexibility", in J. H. Dunning (Ed.), Regions, Globalisation and the Knowledge Economy, pp.286-302, Oxford University Press, Oxford.

Kamińska, W. (2013), "Rural areas in Poland: Educational attainment vs. level of economic development", Questiones Geographicae, Vol. 32/4. http://dx.doi.org/10.2478/quageo-2013-0034

Kowalik, J. and M. Zawada (2017), "Regional diversification of the level of economic development in Poland”, International Journal of Social Sciences, Vol. 3/2, pp. 730-745.

http://dx.doi.org/10.20319/pijss.2016.s21.15661579 
Leydesdorff, L. (2006), The Knowledge Based Economy : Modeled, Measured, Simulated, Universal Publishers, Irvine California.

Li, L. (2005), "The effects of trust and shared vision on inward knowledge transfer in subsidiaries' intraand inter-organizational relationships", International Business Review, Vol. 14/1, pp. 77-95, http://dx.doi.org/10.1016/J.IBUSREV.2004.12.005.

Marinelli, E., J. Edwards and C. Mironov (2017), "Higher Education for Smart Specialisation: The case of North East Romania", JRC Technical Papers, Publications Office of the European Union, Luxembourg.

McCann, P. and R. Ortega-Argilés (2017), "The Intellectual and Practical Bases of the Application of RIS3 within EU Cohesion Policy", in P. McCann, J. Goddard and F. Oort (eds.), The Empirical and Institutional Dimensions of Smart Specialisation, Routledge, London.

McCann, P. van Oort, F. and Goddard, J. (2017), "Introduction to the Empirical and Institutional Dimensions of Smart Specialisation", in P. McCann, J. Goddard and F. Oort (eds.), The Empirical and Institutional Dimensions of Smart Specialisation, Routledge, London.

Moulaert, F. and J. Nussbaumer (2005), "The Social Region", European Urban and Regional Studies, Vol. 12/1, pp. 45-64, http://dx.doi.org/10.1177/0969776405048500.

Nikulin, D. and A. Sobiechowska-Ziegert (2017), "Informal work in Poland - a regional approach", Papers in Regional Science, Vol. 97/4, 1227-1246. http://dx.doi.org/10.1111/pirs.12306.

O'Connor, A. et al. (2018), "Entrepreneurial Ecosystems: The Foundations of Place-based Renewal”, in Blackburn, R. (ed.), Handbook for Entrepreneurship and Small Business Entrepreneurial Ecosystems, Springer, Cham, http://dx.doi.org/10.1007/978-3-319-63531-6_1.

OECD (2016), Employment and Skills Strategies in Poland, OECD Reviews on Local Job Creation, OECD Publishing, Paris, http://dx.doi.org/10.1787/9789264256521-en.

OECD/EU (2017), Supporting Entrepreneurship and Innovation in Higher Education in Poland, OECD Publishing, Paris/EU Publications Office, Brussels, http://dx.doi.org/10.1787/9789264270923-en.

Pilz, M. (2017), "Policy Borrowing in Vocational Education and Training (VET) - VET System Typologies and the "6 P Strategy" for Transfer Analysis", Springer, Cham, http://dx.doi.org/10.1007/978-3-319-47856-2_26.

Pilz, M. (2009), "Initial Vocational Training from a Company Perspective: a Comparison of British and German In-House Training Cultures Modularisation in VET View project Comparative Research in VET View project", Vocations and Learning, http://dx.doi.org/10.1007/s12186-008-9018-x.

Reum, N. (2016), "Demographie und Qualifikation als Herausforderungen für die Fachkräftesicherung. Das Beispiel Elektroindustrie in Deutschland, Polen und den Niederlanden," Geographische Rundschau, Vol. 68/1, pp. 40-45.

Saxenian, A. (2012), "The new argonauts, global search and local institution building", in Cooke, P., M. Parrilli and J. Curbelo (eds.), Innovation, Global Change and Territorial Resilience, Edward Elgar, Cheltenham. 
Statistics of Warsaw (2018), Statistical Office in Warszawa / Warsaw, http://warszawa.stat.gov.pl/en/warsaw/.

Wetzstein, S. and R. Le Heron (2010), “Regional Economic Policy 'In-the-Making': Imaginaries, Political Projects and Institutions for Auckland's Economic Transformation”, Environment and Planning A, Vol. 42/8, pp. 1902-1924, http://dx.doi.org/10.1068/a42248.

Wiemann, J. and M. Fuchs (2018). “The export of Germany's 'secret of success' dual technical VET: MNCs and multiscalar stakeholders changing the skill formation system in Mexico", Cambridge Journal of Regions, Economy and Society, Vol. 11/2, pp. 373-386; https://doi.org/10.1093/cjres/rsy008.

Wiemann, J. et al. (2018). "Duale Ausbildung im Ausland: Ein ,Heimspiel"? Zur Qualifizierung von Produktionsbeschäftigten in deutschen Unternehmen in China, Indien und Mexiko", in Gessler, M., M. Fuchs and M. Pilz (ed.), Konzepte und Wirkungen des Transfers Dualer Berufsausbildung: Länderstudien, Springer VS, Wiesbaden. 


\section{Embedding large enterprises in the local entrepreneurship ecosystem}

This section provides a profile of large domestic and foreign-owned businesses operating in Mazowieckie and discusses opportunities and challenges for leveraging their presence to support entrepreneurship and emerging industries in the region. It includes discussion of corporate entrepreneurship initiatives and the role of intermediary organisations in stimulating large firm engagement in local industry collaborations. It offers policy recommendations and international inspiring policy examples.

\subsection{Introduction}

Established large domestic and foreign-owned businesses around the world are increasingly recognising the importance of entrepreneurship as a catalyst to growth by identifying and creating new opportunities outside of their normal operating activities. The entrepreneurship activities of large firms has become popularised through terms such as corporate entrepreneurship, intrapreneurship and corporate venturing. This entrepreneurial behaviour is commonly associated with the changing nature of business models, whereby R\&D-intensive companies have shifted from internalising innovative and enterprising activities to pursuing them in a more open and collaborative manner.

Defining the scope of entrepreneurial activities in an established business is not straightforward. The can range from encouraging managers and employees to adopt an entrepreneurial mindset, akin to an owner-manager of a small business, to pursuing a more structured range of activities that fall under the banner of corporate entrepreneurship (Hansen and Birkinshaw, 2007). If engaged locally, large firms can promote entrepreneurship and emerging industries in the local entrepreneurship ecosystem by acting as sources of knowledge and innovation for local partners, serving as sophisticated clients for innovative SMEs and start-ups ${ }^{16}$, providing a talent pathway by recruiting skilled staff or even assuming a role in supporting or funding entrepreneurial activity. Entrepreneurially engaged large enterprises therefore play a significant role in acting as conduits, facilitators and embedded actors in entrepreneurship and innovation in a region.

There is an important potential role for regional government in supporting the engagement of large firms in the local entrepreneurship ecosystem. One aspect of this role involves providing brokerage for collaborations with SMEs, entrepreneurs and HEIs and research organisations and others. Another aspect is integrating large firms in entrepreneurship support activities and infrastructures in the region, such as accelerators and incubators in which large firms can invest.

\footnotetext{
${ }^{16}$ Section 3 noted how large firms have driven the emergence of the Mazowieckie photonics industry by acting as customers to SMEs and stimulating new technology and laboratories.
} 


\subsection{Profile of large enterprises in Mazowieckie}

Mazowieckie is home to around $40 \%$ of foreign companies located in Poland and hosts the headquarters of many domestic large firms in the city of Warsaw, particularly in services sectors. Outside Warsaw, the largest firms are present in Płock (printing, agri-food, electronic, and petrochemicals) and Radom (metalworking and telecommunications). As shown in Table 5.1, of the 4437 domestically-owned firms with more than 250 employees in Poland, over 24\% are in Mazowieckie and of those firms around $75 \%$ are based in Warsaw. Almost half of the 100 largest domestically-owned companies in Poland have headquarters in Warsaw, including the largest electricity company in Poland (PGE), the Polish Oil and Gas Company (PGNiG), the engineering and construction company Polimex-Mostostal, PKN Orlen who are one of the largest refiners of crude oil in Central Europe, and GK Polski Holding Farmaceutyczny.

Table 5.1. Headquarters location of Polish-owned large enterprises

\begin{tabular}{lrr}
\hline & \multicolumn{3}{c}{ Total employment in the enterprise } \\
\multicolumn{1}{c}{ Location of headquarters } & $250-999$ employees & 1000+ employees \\
\hline Poland & 3684 & 753 \\
Mazowieckie & 835 & 247 \\
$\quad$ Of which: Warsaw & 606 & 210 \\
\hline
\end{tabular}

While these large firms provide important anchors for the local entrepreneurship ecosystem in Mazowieckie, there is a question as to whether they are entrepreneurial in themselves and/or support entrepreneurial and innovative activity among smaller businesses in the region. Many of these businesses are formerly state owned and they tend not to be particularly innovative. Therefore, while these companies and sectors remain important to the Mazowieckie economy, they do not necessarily represent a strong basis for the diversification of the regional economy.

Mazowieckie (and Warsaw in particular) has also attracted substantial FDI. It is the dominant regional location for FDI in Poland. Overall, the region accounted for $43 \%$ of registered entities with foreign capital and $47 \%$ of the accumulated share capital in companies with foreign capital in Poland. At the end of the third quarter of 2017, the share of entities with foreign capital in the total value of capital expenditures reached $43 \% .{ }^{17}$ At the end of 2015, the number of foreign investors in the region exceeded 1048 entities, with a sectoral breakdown as shown in Table 5.2.

The FDI attracted to Poland over recent decades has tended to be in manufacturing, production and assembly work, with higher value-added activities including R\&D functions retained in home countries. While this is also true of Mazowieckie to some extent, Mazowieckie has attracted investment in a range of sectors. Further, it is notable that a number of firms have located R\&D labs in Warsaw, notably in the digital and electronics sectors. Among the first of these were Samsung Electronics Software R\&D Centre, Motorola Warsaw and General Electric Engineering Design Center (GE EDC). Warsaw

\footnotetext{
${ }^{17}$ Foreign direct investment in Poland, February 2018, Ministry of Enterprise and Technology.
} 
has also attracted a number of knowledge-intensive business and professional services firms, including a number of business process outsourcing (BPO). On the other hand, a key challenge is to stimulate relatively knowledge-intensive FDI to locate in the periphery of the region outside Warsaw.

Table 5.2. Number of foreign investors in Mazowieckie, end 2015

\begin{tabular}{lcc}
\hline \multicolumn{1}{c}{ Sector } & Number FDI entities & Share of FDI entities \\
\hline Business support services & 307 & $29 \%$ \\
Transport & 45 & $4 \%$ \\
\hline Trade & 161 & $15 \%$ \\
\hline Production and sale of transport means & 30 & $3 \%$ \\
\hline Medicine & 30 & $3 \%$ \\
\hline ICT & 94 & $9 \%$ \\
\hline Electronics and electrics & 25 & $2 \%$ \\
\hline Wood and furniture & 21 & $2 \%$ \\
\hline Chemistry & 30 & $3 \%$ \\
\hline Construction industry & 94 & $9 \%$ \\
\hline Food industry & 43 & $5 \%$ \\
\hline Machinery and metal industry & 55 & $11 \%$ \\
\hline Other & 113 & $5 \%$ \\
\hline
\end{tabular}

Source: Investment attractiveness of voivodeships and regions of Poland 2016, Institute for Market Economy Research, Gdansk 2016

FDI has been attracted by low labour costs compared with many regions in other European capital regions (although labour costs are high compared with other Polish regions), high market potential and strong agglomeration economies in terms of large concentrations of skilled labour and R\&D and high transport accessibility. Overall, the ability of Mazowieckie to attract FDI is largely due to the agglomeration effects, knowledge-seeking behaviours of MNEs, and the considerable market potential of the region. In these respects, Mazowieckie is in contrast to many other regions of Poland where low-cost labour continues to be the key attractor.

In addition, five branches of Special Economic Zones (SEZs) (Warmińsko-Mazurska, Tarnobrzeska, Starachowicka, Suwalska and Łódzka) have historically played a role in attracting FDI to the region through offering subsidies and tax breaks. New rules governing SEZs and State Aid procedures in Poland may reduce their cost advantages for FDI in the future. However, SEZs have increasingly come to work more intensively on embedding inward investors in supply chains, skills development and R\&D collaborations in the region 
through working with local governments and the Polish Investment and Trade Agency and engaging more with research organisations.

Despite the high levels of FDI, the extent to which it serves as a catalyst for the wider economic and industrial development of Mazowieckie is questionable. The local supply chains of large domestic and foreign-owned enterprises are relatively undeveloped. Similarly, although there is some evidence of formal university-industry links, given the density of MNEs and large firms in Mazowieckie there are fewer than might be anticipated. There are also few examples of business collaboration between companies and with entrepreneurial start-ups. This is particularly notable in the knowledge-intensive business services sector (Micek, 2015). This lack of embeddedness of large enterprises constrains their capacity to support industrial path development in the region in specialisations that are aligned with their activities, and therefore has significant implications for long-term economic growth in the region.

\subsection{Stimulating corporate entrepreneurship}

Some large firms provide important support to start-ups and scale-ups by operating their own incubators and accelerators, providing mentoring and business advice to start-ups and investing in start-ups. These activities are relatively rare among large firms in Mazowieckie, but there are exceptions.

A notable example is Google, which recently relocated to Warsaw from Krakow. Now located in a former vodka distillery the Google Campus provides a hub for entrepreneurs and start-up founders as well as hosting networking and educational events. In addition, the Google for Entrepreneurs programme provides technical guidance on developing apps and hardware and mentoring and business development support to start-ups firms on the Campus. Nurturing long-term relationships with start-ups that will grow has already resulted in big wins for both the start-ups and for Google.

While this approach has proven particularly successful in the ICT sector, the engagement of corporates with entrepreneurship is less prevalent in other sectors in Warsaw. If large firms in the region are not engaging in initiatives with start-ups independently, the regional government may be able to engage them and support them in publicly-triggered intiatives.

A significant initiative to promote entrepreneurship in the region involves the creation of three Centres of Entrepreneurship, with a fourth in the pipeline. They offer an appropriate and well-constructed infrastructure to facilitate start-ups such as the availability of conference rooms and desk space to hire, and access to advice. However, these initiatives have tended to focus on the start-up community rather than taking an ecosystems-based approach that leverages the presence of larger enterprises.

Box 5.1 offers the inspiring policy practice example of an intermediary organisation between firms and HEIs promoting the engagement of large firms in supporting start-ups in life sciences in Uppsala, Sweden. 


\section{Box 5.1. Role of the Uppsala BIO cluster organisation in promoting large firm entrepreneurship support in Uppsala, Sweden}

\section{Context}

Uppsala is at the north of the Stockholm-Uppsala region in Sweden, which hosts the country's largest life sciences cluster. The broader region is home to 650 life science companies with 20473 employees, over 51\% of total Swedish life sciences employment.

Although Uppsala is a small university city of less than 150000 inhabitants it has become a nexus of life science innovation in its own right. The cluster originated in the 1950s when the Swedish pharmaceutical company Pharmacia relocated its operations from Stockholm to be closer to research collaborators at Uppsala University (Waxell and Malmberg, 2007). Now over 100 life sciences firms operate in Uppsala employing 5000 people in pharmaceutical, biotech, medtech, and diagnostics.

The largest firms in the region include GE Healthcare Biosciences, Fresenius Kabi, and Thermo Fisher Scientific.

\section{Description of the approach}

The Uppsala BIO organisation has provided an important stimulus for local collaboration and engagement by large firms. Uppsala BIO was founded as the operational arm of STUNs - the foundation for collaboration between universities, business, and the public sector in Uppsala. It works with local firms, key national agencies, research labs, the local municipality, the real estate sector, and support organisations to grow and promote the life sciences sector in the region through a range of cluster promotion and investment generating efforts.

Uppsala BIO enjoys strong support from VINNOVA (the Swedish Governmental Agency for Innovation Systems) at the national scale and from founding members Uppsala University, the Swedish University of Agricultural Sciences, and local governmental actors Uppsala County Chamber of Commerce, Uppsala County Administrative Board, Uppsala Regional Council, and the City of Uppsala. It has about 50 partners including all of the largest firms in the region.

Many of the organisation's initiatives focus on connecting members to one another to accelerate the innovation process. These include programmes to help commercialise ideas from the region's research community that can solve unmet medical needs or solve problems in healthcare, drug development, and diagnostics (the BIO-X programme) as well as to connect firms with end-users to test their innovations (the Innovation Akademiska programme). Large firms in the region have also negotiated partnerships with Uppsala BIO in the area of start-up and scale-up support in order to leverage its role as a regional forum and matchmaker.

In 2016, GE Healthcare Life Sciences signed a two-year active technology scouting collaboration agreement with Uppsala BIO. GE wanted to find technologies and equipment to support the production and processing of biopharmaceuticals. The arrangement leveraged Uppsala BIO's networks and staff to find researchers and entrepreneurs working on the cutting edge of research and to broker deals to provide funding, launch start-ups, or enter into commercial partnerships. 
Uppsala BIO has also partnered with large firms outside of the region to support the local entrepreneurship ecosystem. Since 2011, the Swiss-based pharmaceutical company Roche has partnered with Uppsala BIO to support the BIO-X programme though its global programme for open innovation. Through the deal, selected BIO-X projects are co-financed by Roche as well as mentored through its internal entrepreneurial processes.

\section{Success factors}

While the underlying strength of the Uppsala life sciences cluster is undoubtedly its strong tradition of innovation emanating from its universities, research centres, and cutting-edge firms, Uppsala BIO has played an important role in growing the region's entrepreneurship ecosystem and catalysing interfirm partnerships. Its strong focus on supporting commercialisation and entrepreneurship have ensured that the region remains innovative, vibrant, and internationally competitive.

\section{Relevance to Mazowieckie}

This type of initiative in brokering connections between large firms and entrepreneurs for mentoring, financing and client relationships could be pursued by the existing cluster organisations with appropriate resources or by a region-wide specific initiative. It would help to engage more large firms in the region in the support of local entrepreneurship

\section{Further information and sources}

Waxell and Malmberg (2007); Uppsala BIO: https://www.uppsalabio.com/factsfigures/uppsala/

Box 5.2 provides another policy example, focused on how policy has encouraged large firm involvement in entrepreneurship through the development of a business accelerator and incubator by Airbus as part of its participation in the publicly-supported Aerospace Valley cluster in the region around Toulouse in France.

\section{Box 5.2. The Aerospace Valley Cluster and the Airbus BizLab accelerator, Midi-Pyrenees, France}

\section{Context}

The Midi-Pyrenees region in France hosts a significant aerospace cluster centred on Toulouse with over 500 aerospace and aeronautic firms, 124000 jobs in aviation and support industries, and 8500 researchers in corporate and academic labs. The large firm anchor to the cluster is the civil aviation division of Airbus, one of the largest companies in the aerospace industry (Porter and Takeuchi, 2013). Airbus relies on a dense local network of suppliers, contractors, and specialised business services, particularly in the areas of aircraft design, systems integration, marketing, testing, and maintenance. As such, the firm has developed strong locally embedded and globally connected partnerships and established its own programmes to increase regional innovation, entrepreneurship, and augment the talent pool. 


\section{Description of the approach}

Aerospace Valley was created in 2005 as a cluster organisation (Aerospace Valley Institution for Collaboration) and cluster development initiative supported by national, regional and local government, covering the Toulouse and Bordeaux regions in south west France, as part of the national 'pôles de compétitivité programme'. The initiative includes cluster brokerage and networking activities and incentives for collaborative R\&D and innovation. It has administered over EUR 1.2 billion in R\&D funding and manages the ESA Business Incubation Centre (BIC) Sud France, at the tech incubator.

Airbus also maintains its own programmes to catalyse innovation and encourage entrepreneurship. In 2013, it launched BizLab as business accelerator to support local startups and Airbus intrapreneurs in aerospace activities. Start-ups have access to Airbus coaches and experts as well as support staff, Airbus customers and partners, and venture capitalists (information from BizLab). The programme adopts a hybrid open innovation model uniting internal projects with external start-ups to stimulate a broader range of innovative projects and to boost tacit knowledge through experience exchange. It also focuses on developing the capacity of start-ups to deal with large companies. In its first three years BizLab accelerated 50 start-ups, $42 \%$ of which led to contracts with Airbus and other firms. Airbus recently concluded vendor contracts with three of its Indian start-ups Navblue (data-driven management of flight paths), Eflight (flight planning and navigation of private charters), and Airpix (geoanalytical services and imaging) (information from Krishna).

Bizlab outposts subsequently opened in Hamburg (2014), Bangalore (2014), and Madrid (2018) - locations that all hold significance in Airbus's global supply chains - with the stated aim of "widening [....] horizons even further [and] supporting the development of an innovative aeronautical ecosystem" in those regions. In addition to stimulating local entrepreneurship, the BizLab outposts also extend their resources to other target regions. Most recently, Airbus launched the \#Africa4Future to extend BizLab accelerator resources to Sub-Saharan African start-ups with innovative ideas in partnership with the Silicon Cape initiative.

\section{Success factors}

The Aerospace Valley cluster initiative has been important in stimulating the engagement of Airbus in the BizLab accelerator. This is possible because of the underlying innovation strategy of Airbus, which strives to further embed itself in vibrant local entrepreneurship ecosystems and leverage its international reach to tap into developing aerospace clusters.

\section{Further information and sources}

Aerospace Valley: http://www.aerospace-valley.com/en

Airbus: https://www.airbus.com/newsroom/press-releases/en/2018/05/airbus-bizlabexpands-its-global-network-with-new-spanish-campus.html\#media-list-documentdocument-all_ml_0

BizLab: https://www.airbus-bizlab.com/; https://www.airbusbizlab.com/news/africa4future-challenge/view

Krishna: https://yourstory.com/2018/07/airbus-bizlabs-third-cohort-takes-flight-threeindian-startups-bag-vendor-contracts/ 
Porter and Takeuchi (2013)

\subsection{Developing intermediary organisations for network building}

Large enterprises may become closely involved in local networks and interactions where there are positive regional norms and institutions for interaction alongside more formal regional, national and international networks (Hess, 2004). Indeed, if trust is strongly established in a region's entrepreneurship culture, large firm relationships with other stakeholders can emerge spontaneously through informal institutions and the formation of sub-networks (Millar and Choi, 2009).

However, many large firms in Mazowieckie do not have the strong local and civic links that can be found in some other cities and regions such as Krakow and Małopolskie, reflecting the national and international functions of their headquarter activities. Instead, their relationships tend to appear through smaller businesses attempting to ally themselves to a larger company. Thus, whereas in cities such as Berlin smart specialisation is based on large and established business participation, co-operation between large firms is limited in Mazowieckie. The ecosystem is in many senses under construction with the networks between large and small firms still unconnected in many places. One of the barriers has been a lack of tools for nascent entrepreneurs to engage in information platforms to exchange ideas and to get to know stakeholders.

An increasing number of events are starting to bring together regional business, research and education stakeholders in the region, run by various providers and institutions. However, there are two significant limitations. First, they often remain talking shops, rather than providing pathways to produce concrete actions or agreements between stakeholders. Whilst communication between large firms and start-ups, scale-ups, SMEs and HEIs is critical to building social capital and trust-based networks between actors, many stakeholders in Mazowickie are frustrated that few tangible outputs have emerged from these interactions. Stakeholders find it difficult to find common ground where people can work together. Collaboration is often equated with poorly perceived benefits and commitment has been difficult to achieve between established businesses and SMEs, leading to a further asymmetry between formal policy roles and the demands of the region's corporate stakeholders.

Second, local actors are becoming lost in a panoply of competing and often poorly advertised events. The current portfolio of publicly-supported acceleration programmes, seminars, networking events and lectures is typically run by external companies. Efforts to co-ordinate these associations and to promote mutual learning between large enterprises, SMEs and other stakeholders in the region seem ad hoc and lacking a strategic focus. This makes it difficult to present a convincing and strong narrative to larger enterprises with the potential to add clear value to other regional stakeholders.

It is therefore incumbent on the regional government to promote closer links between large enterprises and the local entrepreneurship ecosystem, taking a brokerage or "dealmaker" role (Kemeny et al., 2016). However, the role that regional government takes must recognise that negative attitudes within the region towards public offices have in the past disrupted the full formation of shared platforms of information and active work to connect SMEs to large firms through policy. 
Attention should therefore be given to promotion by the regional government of arm's length intermediary organisations that aim to facilitate formal and informal associations and direct co-operation among regional government, research organisations and businesses (Nauwelaers and Walburn, 2017; Warnke et al., 2016). They could be temporary or permanent in nature and be sustained through physical or virtual platforms. Whilst larger companies are less likely than SMEs to require grants and subsidies for interaction, they can still benefit from the regional intelligence and insight that regional-level intermediaries can provide, as well as their reach beyond the centre of the region in Warsaw. Intermediary organisations can also play an important role in developing a positive image of the region as a start-up hub and talent pool to incumbent large enterprises to encourage greater interaction.

A number of events focused on entrepreneurs have already begun to flourish in Mazowieckie, such as b.Creative Warsaw, Startup Hub Warsaw, and ww.ac and Warsaw Booster 2018. These events focus on fintech and insurtech and provide a blueprint for future approaches to showcasing Mazowieckie and the city of Warsaw as sites of engaged and embedded stakeholders.

There are also some initiatives in the region in which publicly-funded incubators are participating in programmes to encourage the sharing of information between SMEs and large businesses. There have been some notable successes, such as schemes like Startberry, the first private incubator in Warsaw, which was opened by Ernst \& Young and Microsoft. Through patronage, co-organising events, participation in events such as PixelHeaven and Bitspiration, SMEs are increasingly coming into the focus of large enterprises in some hightech sectors.

The Centre for Creativity in Targowa is another example of a micro scale initiative that has been successful in organising networking events, although it has so far involved SMEs far more than large firms.

A further potential policy lever for increasing the engagement of large enterprises in the local entrepreneurship ecosystem is the cluster bodies and industry organisations in Mazowieckie, which include a number of the largest firms in the region as members. Notable examples include the BioTechMed Cluster Mazovia (its largest business partner is Pfizer), Mazovian Chemical Cluster (largest business partner PKN Orlen), Mazovia Cluster ICT (HP and IBM) and the AgroBioCluster (largest business partner Amplus). At present the large firm role in regional innovation and entrepreneurship intiatives is limited, but a boosting of the cluster organisation activities could help engage them further in specific collaborative intiatives.

Continued and boosted regional support for intermediary organisation initiatives of this kind will be important in future efforts to embed large enterprises in the local entrepreneurship ecosystem. Formal membership associations integrating small and larg businesses, alongside universities and regional government can also be effective. In this effort, greater attention should be paid to involving large companies in events and activities and creating a more connected approach across the existing myriad of organisations and initiatives.

\subsection{Conclusions and policy recommendations}

Mazowieckie has attracted a large base of large domestically-owned and foreign-owned enterprises, including many national headquarters a growing professional services sector. 
However, many those firms are not embedded in the regional economy and might be understood as comparatively footloose. Unlike other regions in Poland, Mazowieckie has a "critical mass" of MNEs and large domestic firms, but they are not serving as anchors for wider innovative and entrepreneurial activity. Moreover, the highly concentrated agglomeration means that any attempt to engage these businesses is often limited to Warsaw and consequently the smart specialisation strategy is not regional in scope, whilst labour and skills shortages in Warsaw demand the spreading of development.

The central challenge highlighted in this section is therefore to engage and embed large enterprises in the local entrepreneurship ecosystem, both as entrepreneurial actors themselves and through their engagement with smaller entrepreneurial firms. In this context, this section has identified a number of policy priorities for leveraging the presence of large firms to promote entrepreneurship and emerging industries as well as to help grow and diversify the regional economy beyond the city of Warsaw. Four overarching priorities can be identified, as follows.

\section{Upgrading the functions of the FDI and domestic large firms in the region}

A number of the large businesses located in Warsaw have little connection with other institutions in the city and are primarily located in Warsaw as the capital of the Polish market. This is particularly true for many of the professional services firms that also service other firms with a presence in Warsaw. It is important on the one hand to ensure that the strengths of the region are made clear in inward investment attraction efforts in terms of the capability of the region's skilled labour to deliver higher value activities and in the strong science and research base in the region. At the same time, it is important to work with existing large firms in Mazowieckie to develop their activities through sustained relationship management. There is scope for the regional government and its agencies to assume a more prominent role to ensure that firms are aware of the capabilities in the region. This is critical if Mazowieckie is to attract more R\&D-intensive investments in the future.

\section{Attracting inward investment across the region}

Attracting inward investment across the region is necessary if it is to benefit the periphery as well as the centre. The presence of the SEZs has been effective but there remains an opportunity for areas such as Płock and Radom to compete more strongly as locations for inward investment, especially where there is an existing sectoral strength for the foundation of future smart specialisation. Given the fact that inward investment understandably gravitates to Warsaw, the regional administration could work with the Polish Investment and Trade Agency (PIAH) to develop a stronger offer in other areas of the region.

Clearly, there are limitations to the financial incentives that the regional and local governments can make. However, actions can be undertaken to create conditions that are attractive to potential investors. Facilitating more proactive business networks in Płock and Radom is a way to achieve this as well as promoting the visibility of firms located outside Warsaw to enhance the visibility of these areas as sites for inward investment. This is particularly important where existing firms are in forward looking smart specialisation areas. 


\section{Stimulating corporate entrepreneurship}

Large firms can play important roles in establishing incubators and accelerators and providing a range of mentoring, consulting and financial support to innovative start-ups and scale-ups. There are some examples of this in Mazowieckie, but they are currently limited. There are also a number of important public infrastructures to support start-ups and scale-ups, such as the Centres of Entrepreneurship, in which large firm involvement is relatively limited. A priority for the region is therefore to promote large firm involvement in entrepreneurship support activities to a greater extent, especially in the smart specialisations.

\section{Developing intermediary organisations that include large firms in co-operation networks.}

Intermediary organisations, such as cluster organisations and incubators and organisations running networking events, can play an important role in offering forums for firms and HEIs, and research organisations to meet, exchange information and collaborate. It is important to reinforce these organisations in Mazowieckie, first by connecting them and providing greater regional co-ordination and visibility, and second by ensuring that there are some tangible outputs and outcomes from co-operation. The regional government has a key role to play in supporting and co-ordinating these intermediaries.

\section{Box 5.3. Recommendations on embedding large firms in the local entrepreneurship ecosystem}

1. Communicate and develop a value proposition based on the skills, $R \& D$ and startup activity of the region in order to attract and expand FDI with R\&D activity, higher knowledge intensity and a greater propensity to engage with regional entrepreneurship and innovation.

2. Steer FDI towards the periphery of the region, especially where there are existing smart specialisation strengths there, both by appropriate FDI marketing efforts and efforts to build local capabilities.

3. Approach large firms with a view to engaging them in investments, mentoring and financing of business accesslerators and incubators and involving them in the activities of the Centres of Entrepreneurship.

4. Strengthen intermediary organisations as network hubs between large enterprises, start-ups, scale-ups, SMEs, HEIs and research organisations in the local entrepreneurship ecosystem including incubators, the Centre for Creativity and the cluster organisations. Ensure co-ordination and coherence across the network intermediaries and outcomes for participants. 


\section{References}

Hansen, M.T. and Birkinshaw, J., 2007. The innovation value chain. Harvard business review, 85(6), p.121.

Hess, M. (2004) Spatial relationships? Towards a reconceptualization of embeddedness. Progress in human geography, 28(2), 165-186.

Kemeny, T., Feldman, M., Etheridge, F., \& Zoller, T. (2016). The economic value of local social networks. Journal of Economic Geography, 16, 1101-1122.

Micek G. (2015), FDI Trends in the Business Services Sector: The Case of Poland [w:] B. Galgoczi, J. Drahokoupil, M. Bernaciak (eds.), Foreign Investment in Eastern and Southern Europe after 2008. Still a Lever of Growth? European Trade Union Institute, Brussels,. 297-318.

Millar, C.C. and Choi, C.J. (2009). Networks, social norms and knowledge sub-networks. Journal of Business Ethics, 90(4): 565-574.

Nauwelaers, C. and Walburn, D. (2017) The role of intermediaries in smart specialisation strategies. EU KNowHub. Accessed online: 26/11/2017 http://www.know-hub.eu/knowledge-base/videos/the-roleof-intermediaries-in-smart-specialisation-strategies.html; Smedlund, A., (2006). The roles of intermediaries in a regional knowledge system. Journal of Intellectual Capital 7 (2), 204-220.

Porter, M. and Takeuchi, H. (2013), Aerospace Cluster in the Toulouse Region, Harvard Business School, http://citeseerx.ist.psu.edu/viewdoc/download?doi=10.1.1.571.8563\&rep=rep1\&type=pdf

Warnke, P., Koschatzky, K., Dönitz, E., Zenker, A., Stahlecker, T., Som, O., Cuhls, K. and Güth, S., 2016. Opening up the innovation system framework towards new actors and institutions (No. 49). Fraunhofer ISI Discussion Papers Innovation Systems and Policy Analysis. Accessed online Nov $21^{\text {st }}$ 2017: https://www.econstor.eu/bitstream/10419/129191/1/848865502.pdf

Waxel, A. and A. Malmberg (2007), "What is global and what is local in knowledge-generating interaction? The case of the biotech cluster in Upssala, Sweden", Entrepreneurship and Regional Development, Vol. 19/2, pp. 137-59. 
75 ANNEX A.

Annex A. Data sources for local entrepreneurship ecosystem comparisons 
Table A. 1. Information used for the local entrepreneurship ecosystem index

\begin{tabular}{|c|c|c|}
\hline Pillar & Proxies used & Source of data \\
\hline $\begin{array}{l}\text { 1. Formal } \\
\text { institutions }\end{array}$ & $\begin{array}{ll} & \text { European Quality of } \\
\text { Government Index (EQI) }\end{array}$ & $\begin{array}{l}\text { Charron et. al. (2016), The Quality of } \\
\text { Government EU Regional Dataset, } \\
\text { version Sep16. University of } \\
\text { Gothenburg: The Quality of } \\
\text { Government Institute, } \\
\text { http://www.qog.pol.gu.se }\end{array}$ \\
\hline $\begin{array}{l}\text { 2. Entrepreneurship } \\
\text { culture }\end{array}$ & $\begin{array}{l}\text { - New firms per } 1000 \\
\text { inhabitants }\end{array}$ & OECD Regional Statistics Database \\
\hline $\begin{array}{l}\text { 3. Physical } \\
\text { infrastructure }\end{array}$ & $\begin{array}{ll}\text { - } & \text { Motorways } \\
\text { (kilometre/1 } 000 \mathrm{~km}^{2} \text { ) } \\
\text { - }\end{array}$ & $\begin{array}{l}\text { Charron et. al. (2016), The Quality of } \\
\text { Government EU, Regional Dataset, } \\
\text { version Sep16. University of } \\
\text { Gothenburg: The Quality of } \\
\text { Government Institute, } \\
\text { http://www.qog.pol.gu.se }\end{array}$ \\
\hline 4. Demand & $\begin{array}{l}\text { - GDP at current market } \\
\text { prices, PPP per inhabitant } \\
\text { - } \quad \text { GDP at current market } \\
\text { prices, million PPP } \\
\text { - } \quad \text { Population of the region }\end{array}$ & OECD Regional Statistics Database \\
\hline 5. Networks & $\begin{array}{l}\text { - Number of industrial } \\
\text { enterprises co-operating in } \\
\text { a cluster initiative or other } \\
\text { formalised co-operation as } \\
\text { share of innovation-active } \\
\text { enterprises }\end{array}$ & $\begin{array}{l}\text { Bank Danych Lokalnych GUS } \\
\underline{\text { https://bdl.stat.gov.pl/BDL/ }}\end{array}$ \\
\hline 6. Talent & $\begin{array}{l}\text { - } \% \text { of population } 25-64 \\
\text { years old with tertiary } \\
\text { education (levels } 5-8 \text { ) }\end{array}$ & OECD Regional Statistics Database \\
\hline 7. Finance & $\begin{array}{l}\text { Bank credit and loans as } \\
\% \text { of revenues from total } \\
\text { activity }\end{array}$ & $\begin{array}{l}\text { Bank Danych Lokalnych GUS } \\
\underline{\text { https://bdl.stat.gov.pl/BDL }}\end{array}$ \\
\hline
\end{tabular}


8. New knowledge

9. Intermediate services
- Total expenditure on $\mathrm{R} \& \mathrm{D}$ as \% of regional GDP)

- Employment in knowledge-intensive market services (\% of total employment)

- Value of signed cofinancing agreements from the national innovative economy Operational Programme;

- Value of signed cofinancing contracts for the Regional Operational Programme

- No. of active research units by executive sector total per 100000 inhabitants
OECD Regional Statistics Database

OECD Regional Statistics Database

Bank Danych Lokalnych GUS

https://bdl.stat.gov.pl/BDL/ 


\section{Annex B. Conceptual framework for smart specialisation and path development opportunity assessment}

\section{Introduction}

This annex sets out rationale and approach taken in the OECD local entrepreneurship ecosystems and emerging industries project to assessing the smart specialisation policy of case study regions and the path development opportunities.

\section{Rationale for assessing smart specialisation approaches}

There is widespread agreement among researchers and policy makers that in the context of the globalising knowledge economy promoting innovation-based growth should be the main strategy for regional development in OECD economies. For many years, regional innovation policies emphasised the promotion of high-tech, R\&D-intensive industries in accordance with a "linear view" of innovation. However, policy makers at regional level are increasingly adopting a broader and more comprehensive view of innovation as interactive learning. This recognises that there are a wide range of drivers of innovation further to R\&D driven innovation, including user, market, demand, and employee-driven innovation and social innovation. It also recognises that a "no size fits all" approach must be adopted, given the heterogeneity of OECD countries and regions, which are often at very different stages of economic development (Tödtling and Trippl, 2005).

As a result of this thinking, a new set of place-based "smart specialisation" policies have emerged that seek to drive what Foray calls "positive structural changes" (Foray, 2017, p. 38 ), i.e. changes that promote regional industrial diversification and future competitiveness, leading to economic growth and new job generation. Smart specialisation policies represent a new industrial innovation policy pursuing a high road strategy of innovation-based competition as the sustainable alternative to a downward spiral of cost competition (i.e. the low road strategy) (Milberg and Houston, 2005).

Many regions in the European Union and other OECD countries are adopting smart specialisation (S3) policies. This momentum received a major boost when the EU adopted smart specialisation as an ex ante condition for ERDF expenditures on regional innovation. This requires EU Member States to develop smart specialisation (RIS3) strategies at national or regional levels as the basis for European Structural and Investment Fund interventions in R\&D and innovation. This requirement is expected to be maintained in the next EU financing period after 2020.

However, regional smart specialisation policies are relatively new and require important new policy capacities and approaches at the regional level. The OECD local entrepreneurship ecosystem and emerging industries project includes an assessment and guidance on these policies and policy capacities with a view to assisting regions in developing appropriate policies for supporting innovative start-ups, scale-ups and SME innovation in regional emerging industries. 


\section{What is smart specialisation?}

Radošević considers smart specialisation to be one of the new industrial innovation policy approaches. These new industrial innovation policies are, according to Radošević (2017, p. 9), characterised by the following:

1. No single agent has a total overview of the economy.

2. The key feature is designing a policy process that leads to the "discovery" of new specialisations.

3. Policy making is an endogenous factor in the design and implementation of industrial innovation policy facilitating the process of self-discovery by agents.

The aim of smart specialisation policy is to boost economic growth through economic diversification and new path development, e.g. diversify the economy into technologically more advanced activities that move up the ladder of higher knowledge complexity compared to the present level in the region (Asheim, Grillitsch and Trippl, 2017). The aim is to plan for economic diversification in the short and medium term as well as to adopt a long-term perspective to promote more fundamental structural changes in the economy through transformative activities. It represents an explicit, placed-based approach, emphasising prioritisation, and selectively provides a policy framework for promoting and implementing a broad-based innovation policy through non-neutral, vertical policies.

Smart specialisation is not about "specialisation" as per previous regional development strategies, i.e. a Porter-like cluster strategy, but about diversified specialisation. What this means is that regions should identify strategic sectors - or "domains" - of existing and/or potential competitive advantage, where they can specialise and create capabilities in a different way compared to other regions. A smart specialisation strategy implies maximising the knowledge-based development potential of any region, whether it has a strong or weak R\&D and innovation system or a high-tech or low-tech industrial structure, and can support technological and practice-based innovation (European Commission, 2014, p.2). Regions should diversify their economies primarily based on existing strengths and capabilities by moving into related and unrelated sectors. S3 should build on "each region's strengths, competitive advantage and potential for excellence" (European Commission, 2014, p.2).

"Smart" in the smart specialisation approach refers to the identification of these domains of competitive advantage through what is called the "entrepreneurial discovery process" (EDP). This should embrace all actors with an entrepreneurial mindset, including innovative (Schumpeterian) entrepreneurs at the firm level, institutional entrepreneurs at universities and in the public sector, and place leadership at the regional level who have the capacity to discover domains for securing existing and future competitiveness (Grillitsch and Sotarauta, 2018). Such a broad interpretation of "entrepreneurial discovery" as a public-private initiative avoids the pitfall of ignoring the systemic nature of innovation as interactive learning involving a number of stakeholders. The systems approach to innovation policies also highlights the role of the public sector in driving innovation, as well as the balance between exploration and exploitation (Asheim and Gertler, 2006; Asheim, Grillitsch and Trippl, 2016).

\section{Different regional industrial path development opportunities}

The OECD local entrepreneurship ecosystems and emerging industries project recognises that there are various regional industrial path development opportunities, based on Asheim, 
Grillitsch and Trippl (2017). The path development opportunities range from 'path upgrading', normally taken care of by industry itself in the short and medium term, to 'path diversification' and 'new path creation'. The latter represent transformative activities, which require long-term planning as they represent a jump in novelty and knowledge complexity and therefore also require broader co-operation between industry, universities and governmental agencies on a multiple scales (regional, national and international). The path development types that a region is best placed to pursue depends on its regional industry pre-conditions.

The OECD framework recognises that the industrial pathways that can be developed are influenced by the knowledge base of the region and sector. The knowledge base approach distinguishes between 'analytical/science-based', 'synthetic/engineering-based' and 'symbolic/cultural-based' types of knowledge. It argues that economic diversification and innovation-based competition can be achieved in all industries or sectors yet in different ways, depending on industry-specific modes of innovation and knowledge bases (Asheim, 2007). As this threefold distinction refers to ideal types, most activities are in practice comprised of more than one knowledge base. However, one knowledge base will represent the critical knowledge input which the knowledge creation and innovation processes cannot do without. New combinations of knowledge bases seem to become increasingly important as sources of new path development (Asheim, Grillitsch and Trippl, 2017).

One of the main aims of the knowledge base approach is to provide a theoretical basis for substantiating the point of departure of the RIS3 in the existing strengths of regions, and try to improve and diversify the economy from this starting position. As the strengths of regions can vary from high-tech industries via traditional industries to services and tourism, it was important to move away from the linear innovation model that prioritises analytical, science-based knowledge as the superior type of knowledge to become an innovative economy with rapid economic growth. The knowledge base approach does not discriminate against any type of knowledge and argues that all knowledge types can be the basis for industries pursuing an innovation-based competition.

Table A.2 summarises the main types (path upgrading, path differentiation and path emergence) and mechanisms of regional industrial path development in a detailed way, to demonstrate the various forms of new path development that are on the table for policy makers, and to highlight which resources are required to achieve the various outcomes, from where the resources can be sourced and the outcome of the various forms of new path development. The OECD local entrepreneurship ecosystems and emerging industries project seeks to assess opportunities for industrial path development in case study regions in each of these areas. 
Table A.2 Types and mechanisms of regional industrial path development

\begin{tabular}{|c|c|}
\hline$\underline{\text { Types }}$ & $\underline{\text { Mechanisms }}$ \\
\hline \multicolumn{2}{|c|}{ Path upgrading } \\
\hline $\begin{array}{l}\text { I - Climbing } \\
\text { GPN }\end{array}$ & $\begin{array}{l}\text { Major change of a regional industrial path related to enhancement of } \\
\text { position within global production networks (GPNs); moving up the value } \\
\text { chain based on upgrading of skills and production capabilities }\end{array}$ \\
\hline II - Renewal & $\begin{array}{l}\text { Major change of an industrial path into a new direction based on new } \\
\text { technologies or organisational innovations, or new business models }\end{array}$ \\
\hline $\begin{array}{l}\text { III - Niche } \\
\text { development }\end{array}$ & Development of niches through the integration of symbolic knowledge \\
\hline \multicolumn{2}{|c|}{ Diversification } \\
\hline I - Related & $\begin{array}{l}\text { Diversification into a new related industry for the region building on } \\
\text { competencies and knowledge of existing industries (regional branching) }\end{array}$ \\
\hline II -Unrelated & $\begin{array}{l}\text { Diversification into a new industry based on unrelated knowledge } \\
\text { combinations }\end{array}$ \\
\hline \multicolumn{2}{|l|}{ Emergence } \\
\hline $\begin{array}{l}\text { I - Path } \\
\text { importation }\end{array}$ & $\begin{array}{l}\text { Setting up of an established industry that is new to the region (e.g. through } \\
\text { non-local firms) and unrelated to existing industries in the region }\end{array}$ \\
\hline $\begin{array}{l}\text { II - Path } \\
\text { creation }\end{array}$ & $\begin{array}{l}\text { Emergence and growth of entirely new industries based on radically new } \\
\text { technologies and scientific discoveries or as an outcome of search processes } \\
\text { for new business models, user-driven innovation and social innovation }\end{array}$ \\
\hline
\end{tabular}

Source: Grillitsch, Asheim and Trippl, 2017; Grillitsch, 2018.

Path upgrading points to major intra-path changes, that is, changes of an existing regional industrial path in a new direction. It is possible to distinguish between three sub-categories of upgrading. First, such processes could be triggered by the infusion of new technologies or major organisational changes (renewal). Second, upgrading can be related to an improvement of the position of the regional industry within global production networks (climbing GPNs). This may take place through processes of value enhancement based on the development of more advanced functions, more specialised skills, etc. (Coe et al., 2004; MacKinnon, 2012). Industrial modernisation may lead to these types of upgrading. Third, upgrading might also be related to the development of niches in mature industries, driven by the integration of symbolic knowledge (e.g. in the food and beverage industry, as well as in tourism) (niche development). 
Path diversification based on related knowledge combinations - also referred to as regional branching - implies that new regional industrial paths emerge building on the capabilities in existing industries. Such processes may have several sources. An important mechanism is the diversification of incumbent firms into related fields and industries based on the redeployment of existing assets. Branching can also occur through the foundation of new firms based on competencies in existing industries. Spin-offs from incumbents have been found to play a key role for path branching (Klepper, 2007). Path diversification can also take place through unrelated knowledge combinations (see next section).

Path importation is the least radical type of path emergence referring to the setting up of established industries that are new to the region and not related to other industries present in the region. Such processes could be triggered by the arrival of non-local companies, inflow of skilled individuals with competences not available in the region or innovation partnerships with distant sources. Inward investment by non-local companies is often seen as a key route for path importation, particularly if these firms feature high value-added functions and embed themselves in the regional economy by creating links to regional industry.

Path creation into new industries represents the most radical form of path emergence. It is brought about by the emergence and growth of industries based on new technological and organisational knowledge. There is a growing consensus that chance or historical accidents should not be over-emphasised as causes for new path creation, because they often emerge "in the context of existing structures and paths of technology, industry and institutional arrangements" (Martin and Simmie, 2008, p.186). More specifically, path creation in new industries is often based on the existence of assets, resources or competencies rooted in the area, such as an excellent scientific base (Martin and Sunley, 2006). The emergence of new high-tech and knowledge-intensive industries often hinges on the establishment of new companies and spin-offs (Bathelt, Kogler and Munro, 2010). Also, existing endogenous firms and universities (Tanner, 2014) as well as the inflow of individuals, entrepreneurs and firms from outside (Neffke et al., 2014; Trippl, Grillitsch and Isaksen, 2017) can play a role in "seeding" new paths.

\section{Longer-term new path development strategies}

The framework used for the OECD local entrepreneurship ecosystems and emerging industries project also recognises a tension between short and medium-term path development opportunities and longer-term opportunities. Whilst short and medium-term gains may be had from policy that emphasises path upgrading, attention also needs to be paid to longer-term 'new path development' strategies that support transformative activities in the region. The latter open out the range of path development opportunities and can result in greater productivity enhancement.

Path upgrading is the outcome of incremental innovations in firms. It represents continuity of industrial structures and is first and foremost based on the use of existing knowledge. This will normally represent the most important path to regional economic diversification in the short and medium term. However, limited generation of or access to new complementary knowledge constrain the innovation potential of regional industries and may result in stagnation and decline (path exhaustion) (Trippl and Isaksen, 2016). It is therefore important to also look for sources of diversification in a longer-term perspective to avoid a cognitive and economic lock-in limiting the scope of policy for supporting industrial diversification. The more specialised the regional and national economy is with 
respect to knowledge exploration and exploitation, the more this is the case and the more important policy becomes in supporting the development of diversity.

The least radical form of diversification is related diversification. This can be a very successful strategy in the short and medium-term. However, it is also important to adopt a longer-term strategy of more radical diversification, where the opportunities present themselves, through promoting unrelated diversification into technologically more advanced activities that move up the ladder of higher knowledge complexity compared to the present level in the region.

There are two main routes through which unrelated variety combinations can be achieved; by stimulating unrelated knowledge combinations and by sourcing non-local knowledge. Such new activities may provide more significant benefits but are associated with higher risks compared to the "safer" strategy of supporting industries with higher relatedness to the existing knowledge base, building on local related capabilities, i.e. the related variety approach (Balland et al, 2017). Hidalgo et al. (2002) call such transformative activities "long jumps". Policies to promote long jumps are more challenging, yet "those long jumps are the ones generating new options for subsequent structural transformation." (Hidlago et al, 2002, p. 482).

Many unrelated knowledge combinations are a result of serendipity or chance, and with the increased availability and accessibility of general purpose or key enabling technologies (KET), such as ICT, biotechnology, nanotechnology, etc., more such opportunities might be created in the future.

The KETs will normally be more available globally than locally, and if sourced from outside the region in cases where such technologies are not available locally, does not mean that the region has to develop "new technologies from scratch" (Balland et al, 2017). This underlines the importance of supporting non-local, global knowledge sourcing and links, and designing policies to facilitate this taking place.

In addition, policies have to be in place to secure a high level of absorptive capacity among the region's innovation system actors in order to increase the chances of successful transition to activities based on unrelated knowledge combinations, for example through increasing skills and the capabilities of universities, industries and the public sector in KETs.

The general policy approach to promoting radical forms of new path development is neither a "picking the winner" policy of supporting national champions nor a one-sided indirect, general policy in the form of tax reliefs and subsidies. These alternatives are either too specific, selecting specific industries, or too general, supporting all industries. Instead the approach suggested to developing more radical new industrial pathways in a region in the long-term involves a three-fold strategy working across the whole regional innovation system involving (Asheim and Moodysson, 2017):

1. Building and upgrading KET competences aimed at strengthening the 'knowledge exploration' capacity of the region's firms and innovation system.

2. Supporting strategic $R \& D$ focusing on new product innovations based on unrelated variety to increase the 'knowledge exploration' capacity of the region's firms and innovation system.

3. Supporting new product development based on unrelated variety to boost the 'knowledge exploitation' capacity of firms. 
This approach should be pursued at the same time as efforts to encourage short and medium-term path upgrading and extension.

\section{Regional pre-conditions for industry path development}

Regional pre-conditions have an important influence on the opportunities for industy path development. These pre-conditions can be assessed on two main dimensions. The first dimension refers to the degree of industry diversification and innovation capacity of the region, i.e. the extent to which a region is specialised or diversified and the extent to which it has high or low innovation capacity. A characterisation of different types of regions on this classification is given in Table A.3.

Table A.3 Types of regional pre-conditions for industrial path development by regional industry diversification and innovation capacity

\begin{tabular}{lll}
\hline \multicolumn{1}{c}{ Diversified } & \multicolumn{1}{c}{ Specialised } \\
\hline $\begin{array}{l}\text { High } \\
\text { innovation } \\
\text { capacity }\end{array}$ & $\begin{array}{l}\text { Metropolitan/city regions in } \\
\text { Northern and Western Europe }\end{array}$ & $\begin{array}{l}\text { Industrial regions in Northern and } \\
\text { Western Europe }\end{array}$ \\
$\begin{array}{l}\text { Low } \\
\text { innovation } \\
\text { capacity }\end{array}$ & $\begin{array}{l}\text { Larger cities in Southern and } \\
\text { Eastern Europe }\end{array}$ & $\begin{array}{l}\text { Southern and Eastern peripheral } \\
\text { regions }\end{array}$ \\
\hline
\end{tabular}

Source: Author.

A second dimension of regional pre-conditions for industrial pathway development is the level of "system differentiation" of the regional innovation system. This can be described by actors, networks and institutions. Actors may be further characterised by their capabilities, the variety of types of actors and by the scale or number of actors. Networks can be found within sectors, between sectors and constituting local-global relations. Institutions can be described by quality of governance, adequate policy repertories, governance processes and entrepreneurial culture (Grillitsch, 2018). The greater the level of system differentiation in a region, the greater its capacity for designing and implementing policy measures to promote industry transition through smart specialisation policies. Further specifications of various indicators of system differentiation are provided in Table A.4. (Grillitsh, 2018).

Table A.4. Factors influencing system differentiation for industrial diversification policy

\begin{tabular}{ll}
\hline System elements & Indicators of differentiation \\
\hline Actors & \\
Capabilities & $\begin{array}{l}\text { Use of cutting-edge knowledge and technologies, high resource endowment } \\
\text { and financial capabilities }\end{array}$ \\
\hline
\end{tabular}




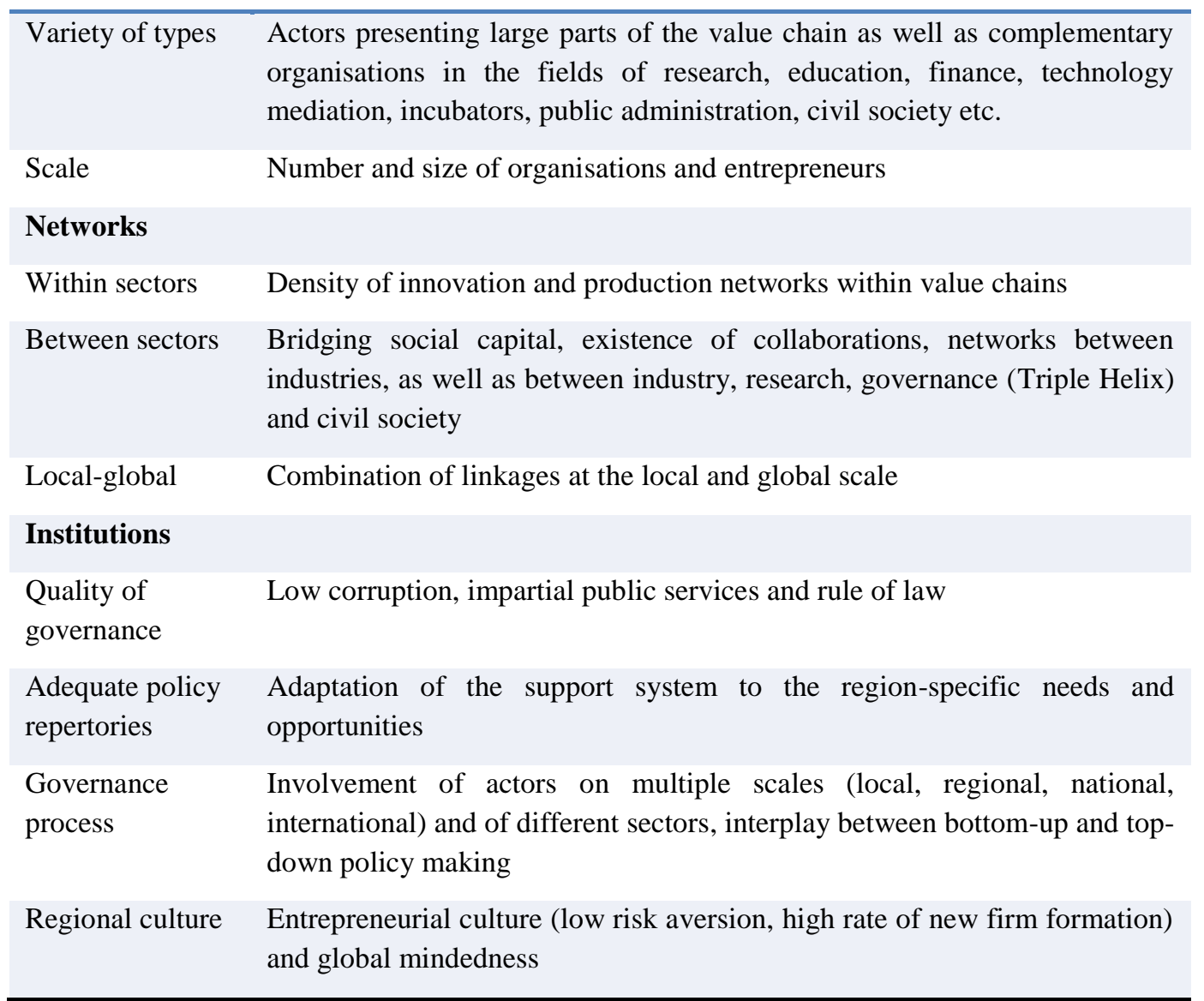

Source: Grillitsch, 2018.

It is possible to characterise the path development opportunities in a region on these two dimensions. Smart specialisation policy in regions with diversified industry, high innovation capacity, and high system diversification can be seen to have greater probabilities of favouring longer-term new path development, whereas those with specialised industry, low innovation capacity and low system diversification have greater probabilities of being able to achieve more modest path upgrading.

\section{References}

Asheim, B. (2007), "Differentiated knowledge bases and varieties of regional innovation systems", Innovation: The European Journal of Social Science Research, Vol. 20/3, pp. 223-241, http://dx.doi.org/10.1080/13511610701722846

Asheim, B. and M. Gertler (2006), The Geography of Innovation, in J. Fagerberg, D. C. Mowery and R. R. Nelson (Eds.) The Oxford Handbook of Innovation, Oxford University Press, Oxford.

Asheim, B. and J. Moodysson (2017), "Innovation Policy for Economic Resilience: The Case of Sweden", Papers in Innovation Studies, CIRCLE, University of Lund, Sweden. 
Asheim, B., M. Grillitsch and M. Trippl (2016), "Regional Innovation Systems: Past - Presence Future", in Shearmur, R., C. Carrincazeaux and D. Doloreux (eds.), Handbook on the Geographies of Innovation, Edward Elgar, Cheltenham.

Asheim, B., M. Grillitsch and M. Trippl (2017), "Introduction: Combinatorial Knowledge Bases, Regional Innovation, and Development Dynamics”, Economic Geography, Vol. 93/5, pp. 429-435, http://dx.doi.org/10.1080/00130095.2017.1380775.

Balland, P., R. Boschma, J. Crespo, and D. Rigby (2017), "Smart Specialization Policy in the EU: Relatedness, Knowledge Complexity and Regional Diversification”, SSRN Electronic Journal, http://dx.doi.org/10.2139/ssrn.2995986.

Bathelt, H., D. Kogler and A. Munro (2010), "A knowledge-based typology of university spin-offs in the context of regional economic development", Technovation, Vol. 30/9-10, pp. 519-532, http://dx.doi.org/10.1016/J.TECHNOVATION.2010.04.003

Coe, N., M. Hess, H. Wai-chung Yeung, P. Dicken and J. Henderson (2004), "'Globalizing' regional development: a global production networks perspective", Transactions of the Institute of British Geographers, Vol. 29/4, pp. 468-484, http://dx.doi.org/10.1111/j.0020-2754.2004.00142.x

European Commission (2014), National/Regional Innovation Strategies for Smart Specialisation (RIS3), http://ec.europa.eu/regional_policy/sources/docgener/informat/2014/smart_specialisation_en.pdf.

Foray, D. (2017), “The Economic Fundamentals of Smart Specialization Strategies”, in Radošević, S. et al. (eds.), Advances in the Theory and Practice of Smart Specialization, Academic Press, Waltham MA.

Grillitsch, M. (2018), "Place-based entrepreneurship and innovation policy for industrial diversification", Paper prepared for the OECD LEED Programme, OECD, Paris.

Grillitsch, M. and M. Sotarauta (2018), "Regional Growth Paths: From Structure to Agency and Back", Papers in Innovation Studies, Paper 2018/1, CIRCLE, Lund University, Sweden. https://ideas.repec.org/p/hhs/lucirc/2018 001.html

Hidalgo, C. et al. (2002), "The Product Space Conditions the Development of Nations", Science, Vol. 297/5586, pp. 1551-5.

Klepper, S. (2007), "Disagreements, Spinoffs, and the Evolution of Detroit as the Capital of the U.S. Automobile Industry", Management Science, Vol. 53/4, pp. 616-631, http://dx.doi.org/10.1287/mnsc.1060.0683

MacKinnon, D. (2012), "Beyond strategic coupling: reassessing the firm-region nexus in global production networks", Journal of Economic Geography, Vol. 12/1, pp. 227-245, http://dx.doi.org/10.1093/jeg/lbr009

Martin, R. and J. Simmie (2008), "Path dependence and local innovation systems in city-regions", Innovation: Management, Policy and Practice, http://dx.doi.org/10.5172/impp.453.10.2-3.183

Martin, R. and P. Sunley (2006), "Path dependence and regional economic evolution", Journal of Economic Geography, Vol. 6/4, pp. 395-437, http://dx.doi.org/10.1093/jeg/lbl012 
Milberg, W. and E. Houston (2005), "The high road and the low road to international competitiveness: Extending the neo-Schumpeterian trade model beyond technology", International Review of Applied Economics, Vol. 19/2, pp. 137-162, http://dx.doi.org/10.1080/02692170500031646

Neffke, F. et al. (2014), "Agents of structural change The role of firms and entrepreneurs in regional diversification”, https://www.fiw.ac.at/fileadmin/Documents/Veranstaltungen/16._Workshop/paperagents-of-structural-change.pdf (accessed on 15 June 2018).

Radošević, S. (2017), “Assessing EU Smart Specialisation Policy in a Comparative perspective”, in Radošević, S. et al. (eds.), Advances in the Theory and Practice of Smart Specialization, Academic Press, Waltham MA.

Tanner, A. (2014), "Regional Branching Reconsidered: Emergence of the Fuel Cell Industry in European Regions", Economic Geography, Vol. 90/4, pp. 403-427, http://dx.doi.org/10.1111/ecge.12055

Tödtling, F. and M. Trippl (2005), "One size fits all?: Towards a differentiated regional innovation policy approach”, Research Policy, Vol. 34/8, pp. 1203-1219, http://dx.doi.org/10.1016/J.RESPOL.2005.01.018.

Trippl, M. and A. Isaksen (2016), "Path Development in Different Regional Innovation Systems: A Conceptual Analysis", in M. Davide Parrilli, Rune Dahl Fitjar, A. (ed.), Innovation Drivers and Regional Innovation Strategies, Routledge, London. https://www.taylorfrancis.com/books/e/9781317370246/chapters/10.4324\%2F9781315671475-12).

Trippl, M., M. Grillitsch and A. Isaksen (2017), "Exogenous sources of regional industrial change", Progress in Human Geography, p. 030913251770098, http://dx.doi.org/10.1177/0309132517700982 